\title{
Fair optimal tax with endogenous productivities
}

Citation for published version (APA):

Fleurbaey, M., \& Valletta, G. (2013). Fair optimal tax with endogenous productivities. Maastricht University, Graduate School of Business and Economics. GSBE Research Memoranda No. 024 https://doi.org/10.26481/umagsb.2013024

Document status and date:

Published: 01/01/2013

DOI:

10.26481/umagsb.2013024

Document Version:

Publisher's PDF, also known as Version of record

\section{Please check the document version of this publication:}

- A submitted manuscript is the version of the article upon submission and before peer-review. There can be important differences between the submitted version and the official published version of record.

People interested in the research are advised to contact the author for the final version of the publication, or visit the DOI to the publisher's website.

- The final author version and the galley proof are versions of the publication after peer review.

- The final published version features the final layout of the paper including the volume, issue and page numbers.

Link to publication

\footnotetext{
General rights rights.

- You may freely distribute the URL identifying the publication in the public portal. please follow below link for the End User Agreement:

www.umlib.nl/taverne-license

Take down policy

If you believe that this document breaches copyright please contact us at:

repository@maastrichtuniversity.nl

providing details and we will investigate your claim.
}

Copyright and moral rights for the publications made accessible in the public portal are retained by the authors and/or other copyright owners and it is a condition of accessing publications that users recognise and abide by the legal requirements associated with these

- Users may download and print one copy of any publication from the public portal for the purpose of private study or research.

- You may not further distribute the material or use it for any profit-making activity or commercial gain

If the publication is distributed under the terms of Article $25 \mathrm{fa}$ of the Dutch Copyright Act, indicated by the "Taverne" license above, 


\section{Maastricht University}

Marc Fleurbaey, Giacomo Valletta

Fair Optimal Tax with

Endogenous Productivities

$\mathrm{RM} / 13 / 024$

\section{GSBE}

Maastricht University School of Business and Economics

Graduate School of Business and Economics

P.O Box 616

NL-6200 MD Maastricht

The Netherlands 


\title{
FAIR OPTIMAL TAX WITH ENDOGENOUS
}

\section{PRODUCTIVITIES*}

\author{
Marc Fleurbaey And Giacomo Valletta $^{\ddagger}$
}

April 2013

\begin{abstract}
What is a good incentive-compatible policy when one wants to respect individual choices of labor and human capital but eliminate inequalities due to unequal access to human capital and different returns to human capital, and when earnings and human capital expenditures are the only verifiable variables? We propose a social ordering that incorporates this goal and we analyze the evaluation of tax reforms and the properties of optimal linear and non-linear taxes. For reform evaluation and for optimal non-linear taxation, the focus is on the situation of individuals with the most disadvantaged characteristics who work full time and spend a certain (high) amount in human capital.
\end{abstract}

Keywords: tax reforms, optimal tax, fairness, endogenous skills, human capital.

JEL Classification: D63, D71.

\section{Introduction}

Since the seminal contribution of Mirrlees [31] the literature on income taxation has often assumed that agents' earning abilities (i.e., their marginal labor productivities) are fixed and independent of any factor that is subject to their choices. This is not very realistic. Workers can, to some

${ }^{*}$ We thank François Maniquet and Emmanuel Saez for comments and suggestions, as well seminar and conference participants at CORE, Institute for Global Studies, Luiss, the Social Choice and Welfare Meeting 2012 (New Delhi) and the ASSA meeting 2013 (San Diego). A first draft of this paper was prepared while G. Valletta was visiting the Institute for Global Studies (Paris), to which he is grateful for hospitality and financial support.

${ }^{\dagger}$ Princeton University, USA. Email: mfleurba@princeton.edu.

¥Maastricht University, Netherlands - Email: g.valletta@maastrichtuniversity.nl. 
extent, affect their productivity by making certain choices about their level of human capital (health, training). So, a system of human capital subsidies might be considered for redistributing income across agents and better tackling the trade-off between efficiency and equity. In addition, the assumption of exogenous skills excludes certain normative considerations. Assume one wants to compensate agents for their lack of productivity as long as this is not their choice. A model where productivity is exogenous does not allow to distinguish between a low-skilled agent who has chosen her lower productivity and another low-skilled agent who has instead suffered from various impediments which have prevented her from acquiring a higher skill.

We propose a model where agents differ in three characteristics. First, agents differ in their human-capital-dependent earning ability. Typically human capital positively affects productivity, and a higher (marginal) productivity is typically reflected by an increased wage. ${ }^{1}$ However the impact of human capital on earning ability can vary across agents. In particular, an individual might be more productive than another one for any possible level of human capital and such heterogeneity might be due to innate factors, or social connections, which are beyond their responsibility.

Second, in order to reach a certain level of human capital, different agents might have to face different intrinsic costs. That is, agents have a different human capital disposition. For instance, one could think of health. Two agents might both be willing to be in good health but one of them suffers from a congenital disease and only an expansive treatment allows her to be in good health: she has a worst human capital disposition than the other one. Once again these differences are typically due to factors that are beyond agents' responsibility: agents may have a different human capital disposition because of genetic factors, ${ }^{2}$ their upbringing or the social context they live in. ${ }^{3}$ We will refer to these two characteristics, earning ability and human capital disposition, as the circumstances of an agent.

Third, agents have heterogeneous preferences over consumption, labor and human capital: they typically make different choices about their consumption, about their labor time, and about their human capital level.

\footnotetext{
${ }^{1}$ This is certainly the case for health care as shown, among others, by Mushkin [32], Grossman and Benham [21], Luft [28].

${ }^{2}$ Christensen et al. [10] shows that approximately a quarter of the variation in the liability to self-reported health and the number of hospitalizations could be attributed to genetic factors.

${ }^{3} \mathrm{~A}$ high socio-economic status is typically associated with better health and longer life, see for example Reid et al. [34], or Marmot el al. [30].
} 
In such a framework we study criteria to evaluate policies aiming at combining income tax with a system of subsidies on human capital expenditure. More precisely, a tax policy is a function defining a transfer of income depending both on the level of earnings and on the human capital expenditure.

To perform our analysis we use specific social preferences that incorporate efficiency and fairness concerns. The standard utilitarian approach would not only lead to an intractable problem (given the complexity of the model) but, as also recently stressed by Piketty and Saez [33], it would not allow us to incorporate the value judgment that inequalities due to circumstances are more offensive than inequalities due to differences in preferences. Boadway et al. [4] introduced weights in the social welfare function in order to accommodate this idea, but they did not provide a precise methodology to determine suitable weights. Such a methodology has been developed by Fleurbaey and Maniquet, ${ }^{4}$ and we borrow it here. We use a social welfare ordering which is based on a particular index of well-being that represents agents' preferences. An individual's well-being is measured by the amount of money that would leave her indifferent between her current situation and being free to choose her labor time and her human capital expenditure from a hypothetical budget set where both her earning ability and her human capital disposition are equal to the average ones. Such a measure of individual well-being does not require any other information about individuals' utilities than their ordinal non-comparable preferences, a convenient property that follows from the attribution of responsibility for preferences and subjective utility to the individuals themselves. The well-being levels of agents, at any allocation, are then aggregated using the leximin criterion.

We look first at the problem of assessing tax reforms. As a matter of fact, actual tax policy debates revolve around marginal changes of a given status quo rather then radical changes aiming at an ideal tax policy. In this respect a policy-maker might consider useful to be able to relate explicit value judgments to simple criteria to compare different tax policies. In spite of the complexity of the model we are able to provide a simple criterion for the comparison of non-linear tax policies in a setting where only earned income and human capital expenditure are observable. This task is made possible by the fact that we are using social preferences of the leximin type. Indeed, in order to understand which part of the tax function should be changed in priority, in case of reform, one needs to spot the worst-off agent at the allocation generated by the tax function under

\footnotetext{
${ }^{4}$ Fleurbaey [14], Fleurbaey and Maniquet [16][17].
} 
examination. It turns out that the focus should always be on a specific region of the budget set shaped by the tax function. In order to evaluate a certain tax scheme the policy maker should look primarily at the part of the budget set that is attainable by an agent with the worst earning ability and the worst human capital disposition. However the worst-off agent at the allocation generated by a certain tax policy does not actually need to be an agent whose circumstances are the worst in society. Nonetheless, giving priority to the region of the budget set that is attainable by disadvantaged agents means that the main concern of the policy maker should not necessarily be to improve the condition of agents with a low level of human capital but rather look, more in general, at agents for whom acquiring human capital is particularly difficult (i.e., agents with a bad human capital disposition).

We also study the shape of the optimal income schedule. We consider first the case of linear taxes. It turns out that in certain instances taxing human capital expenditure might be optimal. Interestingly the occurrence of a negative subsidy rate on human capital expenditure is closely related to the distribution of preferences across the population. For example a high sensitivity of human capital expenditures to subsidies together with a low sensitivity of earnings to tax will bring high tax rates and low subsidy rates. The same happens if the worst-off agent spends considerably less than average in human capital. On the other hand, when we turn our attention to the nonlinear case we find that the agents who are at the focus of social preferences are typically subsidized, although their marginal subsidy may be null. The agent who receives the highest subsidy is typically some disadvantaged agent who works full time and who, among all the agents with the poorest human capital disposition, has a high (sometimes the highest) human capital expenditure.

The paper is organized as follows. Section 2 reviews the related literature. Section 3 introduces the model and the notation. Section 4 introduces the notion of social preferences used in the paper and the ethical requirements they bear. Section 5 proposes a way to compare different arbitrary tax policies. Section 6 describes some features of the optimal linear tax schedule. Section 7 describes some features of the optimal non-linear tax schedule. Section 8 deals with the case of observable human capital. Section 9 concludes. The appendix briefly resumes the axiomatic analysis. 


\section{Related literature}

The generality of our model allows to build several links with different strands of the literature on optimal income taxation depending on how one interprets human capital.

One can think of human capital as the level of education of agents. A first idea found in the literature on education and taxation is that appropriate education subsidies may offset the disincentives to work and acquire education induced by a progressive income tax (Krueger and Ludwig [27]). However this efficiency effect may be partly counterbalanced by a redistribution effect due to the fact that education may be associated with greater ability, as analyzed by Maldonado [29] and Bovenberg and Jacobs [6]. A striking result in these papers is that the optimal policy will simply deduct education expenditures from taxable income under specific conditions about the earnings function. These conditions are studied in detail by Jacobs and Bovenberg [25] and involve comparing the degree of complementarity between education and labor on one hand and between education and ability on the other hand. When earnings are equal to the product of labor and a wage rate that depends on education expenditures and individual ability, as in Maldonado [29] and in our model, the condition for full tax deduction is that the elasticity of the wage rate with respect to education expenditures be the same for all individuals (i.e., be independent of ability) —if it increases with ability, then education is not fully deductible.

This result is obtained in models in which individual preferences are indifferent to the education level, so that efficiency dictates treating education as an intermediate good for the investment decision should not be distorted. In our paper we allow individuals to care about their level of human capital. Our results on the optimal rate of subsidy (or tax) on human capital expenditures therefore depend not only on properties of the earnings function, but also on the distribution of preferences in the population. We actually obtain the possibility that human capital expenditures may be taxed (in gross terms) when they exceed the level spent by the worst-off (in the case of a non-linear tax), or when the worst-off spend less than average (in the case of linear taxes).

One can also interpret human capital as the level of health of the individuals. Interestingly most of the literature focusing on the taxation/subsidization of health care does not allow for endogenous earning abilities. Health is rather considered as a factor that can randomly affect the amount of resources available to an individual (see, among others, Blomqvist and Horn [2], Cremer

and Pestieau [9], Henriet and Rochet [23] and Rochet [36]). The main objective of these papers is 
to understand whether covering people against such a risk, by means of a public health insurance, is welfare improving or not from an ex ante-perspective. In this respect, health insurance can indeed be used as a redistribution device provided that the probability of being ill is comparatively larger for agents at the bottom of the income distribution.

All the papers quoted so far have focused on social objectives defined in terms of utilitariantype social welfare functions. Such social welfare functions are typically not precisely specified, and the objective of redistributing resources only depends on their degree of concavity. Moreover they rely on specific assumptions about preferences such as separability, and generally assume that all individuals have the same utility function. A common result of this approach is that marginal tax rates are everywhere positive. Interestingly, this result still holds in situations where the maximin criterion is used. Boadway and Jacquet [3] provide minimal conditions for the marginal tax rate to be not only positive but also decreasing throughout the whole skill distribution.

Things become more complex if individual preferences are assumed to be heterogeneous. Papers that deal with preference heterogeneity exclusively focus on income taxation, and agents' productivities are heterogeneous but exogenous (see, among others, Boadway, Marchand, Pestieau and Racionero [4], Choné and Laroque [7] [8], Jacquet and Van de gaer [26], Saez [37]). As noted in the introduction, a key difficulty that comes with preference heterogeneity is that in order to sum the utility levels of agents endowed with different preferences one needs a cardinalization of utilities that typically lacks a solid normative foundation. Moreover, as well-known in the literature on social justice, and recently emphasized in the taxation literature by Jacquet and Van de gaer [26] and Saez and Stantcheva [38], with double heterogeneity traditional welfarist criteria (including utilitarianism) might lead to policy recommendations that are unappealing in at least two respects. First, they fail to compensate agents for inequalities deriving from characteristics they cannot be held responsible for. Second, depending on the weights assigned to different kinds of preferences the optimal policy might require to redistribute income even if all agents have the same abilities.

In order to tackle these difficulties we use a particular definition of social welfare for a population that is heterogeneous in three dimensions (preferences, human capital disposition, earning abilities). Such a social objective is derived from fairness principles that capture the idea that inequalities due to circumstances are unfair whereas inequalities due to differences in preferences and utilities are acceptable. ${ }^{5}$ In this respect we adopt and extend a methodology developed by

\footnotetext{
${ }^{5} \mathrm{~A}$ frequent criticism is that differences in utilities may reflect different capacities for enjoyment that should be
} 
Fleurbaey and Maniquet ([16], [17], [18]). In general their analysis is made under the assumptions that labor productivity is exogenous and that agents are not considered responsible for it. ${ }^{6} \mathrm{~A}$ common feature of the (optimal) tax policies they propose is that poor hardworking agents (i.e., agents earning the minimum wage and working full time) should be granted the greatest subsidy in the whole population.

It is interesting to notice that adding endogenous earning abilities but keeping the income tax function as the sole instrument (i.e., human capital expenditure not being observable) would already alter the results in a certain direction. Social priority would be granted to a wider range of incomes: not only the minimum wage but the whole range of earnings attainable to the agents with the worst earning ability. Moreover, in establishing how earnings (not only within this particular range) should be treated by the tax function, one should also take into account the higher responsiveness of earnings to taxation (since earnings also depends on human capital).

Valletta [39] introduced a simplified version of our model, in which health influences productivity, the choice of the health status is dichotomous, and there are only two types of earning abilities and health dispositions in the population. This paper provides an axiomatic characterization of a social ordering function that can be easily extended to our model, and we will retain it here.

Finally, our paper also relates to the literature on commodity taxation. In their seminal contribution Atkinson and Stiglitz [1] showed that within a population of individuals who differ only in their labor productivity, if preferences are separable between labor and consumption of other goods, then commodity taxation cannot increase welfare above the level obtained with an optimal income tax alone. Many studies have examined the robustness of this result (see Boadway and Pestieau [5] for an overview). It does not hold in our framework if applied to human capital expenditures. This is explained by the fact that human capital is here a special commodity which affects the agents' productivity, and agents have to face unequal costs in order to acquire it.

compensated as well. But if individuals differ in such capacities this should be explicitly introduced in the model, as additional objects of preferences. We assume that our model fully describes the object of individual preferences, so that differences in utilities cannot be due to inequalities in additional internal resources that the individuals care

about. For a study of compensation for inequalities in internal resources, see Fleurbaey [14].

${ }^{6}$ See, however, Fleurbaey [14] (p. 149-150) for a brief analysis of endogenous skills. 


\section{The model}

We consider a set of economies, each with a finite set of agents $N \subset \mathbb{N}$. There are three goods: consumption, labor and human capital. A bundle for agent $i \in N$ is a triple $z_{i}=\left(c_{i}, l_{i}, h_{i}\right)$, where $c_{i}$ is consumption, $l_{i}$ is labor, and $h_{i}$ is human capital. In particular, $c_{i} \in \mathbb{R}_{+}$will be interpreted here as the expenditure on ordinary consumption goods, excluding human capital expenditure. As usual for this kind of analysis, $l_{i} \in[0,1]$. Human capital is also a continuous variable, and for simplicity we assume $h_{i} \in[0,1] .^{7}$ To sum up, the consumption set is $X=\mathbb{R}_{+} \times[0,1] \times[0,1]$. An allocation describes each agent's bundle, and will be denoted by $z=\left(z_{i}\right)_{i \in N}$.

Agents have three characteristics: their personal preferences, their earning ability and their human capital disposition.

For each agent $i \in N$, preferences are denoted $R_{i}$ and $z_{i}^{\prime} R_{i} z_{i}\left(\operatorname{resp} z_{i}^{\prime} P_{i} z_{i}, z_{i}^{\prime} I_{i} z_{i}\right)$ means that bundle $z_{i}^{\prime}$ is weakly preferred (resp. strictly preferred, indifferent) to bundle $z_{i}$. Let $R=\left(R_{i}\right)_{i \in N}$ denote the population profile of preferences. We restrict our attention to preferences which are continuous, strictly monotonic (increasing in $c_{i}$ and $h_{i}$, decreasing in $l_{i}$ ) and convex. Let $R=$ $\left(R_{i}\right)_{i \in N}$ denote the profile of preferences of the whole population.

The marginal productivity of labor is assumed to be an increasing function of human capital, $w_{i}\left(h_{i}\right)$ with $w(0) \geq 0$. It is measured in consumption units per full time labor, so that for any $l_{i}$, $w_{i}\left(h_{i}\right) l_{i}$ is the agent's pre-tax income (earnings). Agents are endowed with different such functions. For some $i, j \in N$ we say that agent $i$ is more productive than agent $j$ if $i$ 's productivity function dominates $j$ 's, that is, if $w_{i}(h) \geq w_{j}(h)$ for all $h$. Let $w()=.\left(w_{i}(.)\right)_{i \in N}$ denote the profile of individual productivity functions for the whole population.

Finally, every individual $i$ has a mapping $m_{i}\left(h_{i}\right)$ describing how much of human capital expenses must be made in order to bring her to a human capital level $h_{i}$. We assume that this function satisfies $m_{i}(h)=0$ for $h \leq \underline{h}_{i}$, and belongs to two possible classes. In the first class, $m_{i}$ is increasing over $\left[\underline{h}_{i}, \bar{h}_{i}\right]$, and is equal to $+\infty$ for $h>\bar{h}_{i}$. In the second class, it is increasing over $\left[\underline{h}_{i}, \bar{h}_{i}\right)$, tends to $+\infty$ for $h \rightarrow \bar{h}_{i}$, and is equal to $+\infty$ for $h \geq \bar{h}_{i}$. It is possible to have $\underline{h}_{i}=0$ and/or $\bar{h}_{i}=1$. We define the inverse function $m_{i}^{-1}: \mathbb{R}_{+} \rightarrow\left[\underline{h}_{i}, \bar{h}_{i}\right]$ (first class) or $m_{i}^{-1}: \mathbb{R}_{+} \rightarrow\left[\underline{h}_{i}, \bar{h}_{i}\right.$ ) (second class) by $m_{i}^{-1}(m)=\underline{h}_{i}$ for $m=0, m_{i}^{-1}(m)=h$ such that $m_{i}(h)=m$ for $0<m<m_{i}\left(\bar{h}_{i}\right)$,

\footnotetext{
${ }^{7} \mathrm{~A}$ more general model, describing human capital as a multidimensional variable, would be certainly more realistic and most of the results, in principle, would still hold. However this would render the analysis quite cumbersome.
} 
and in the first class, $m_{i}^{-1}(m)=\bar{h}_{i}$ for $m \geq m_{i}\left(\bar{h}_{i}\right)$. The function $m_{i}($.$) captures all factors$ that determine the human capital costs, including not only purely human capital features but also social and economic characteristics which influence $i$ 's human capital. Again, agents are eventually endowed with different such functions. For some $i, j \in N$ we say that agent $i$ has a (weakly) worse human capital disposition than agent $j$ if $m_{i}(h) \geq m_{j}(h)$ for all $h$. Let $m()=.\left(m_{i}(.)\right)_{i \in N}$ denote the profile of human capital dispositions for the whole population.

An economy is denoted $e=(R, w(),. m()$.$) . We let the population N$ remain implicit in this description of an economy. Let $\mathcal{D}$ denote the set of economies complying with our assumptions.

The set of allocations to be ranked by a social ordering is $Z=X^{|N|}$. This set includes feasible and non-feasible allocations. An allocation is feasible if

$$
\sum_{i=1}^{n} c_{i}+\sum_{i=1}^{n} m_{i}\left(h_{i}\right) \leq \sum_{i=1}^{n} w_{i}\left(h_{i}\right) l_{i}
$$

In absence of redistribution, the budget set of each agent $i \in N$ is equal to the possible combinations of consumption, labor and human capital that are attainable for her, given her earning ability and her human capital disposition. In the first best context, one can use lump-sum transfers in order to redistribute income across agents. Then, agent $i$ 's first-best budget set is, letting $t_{i}$ denote the transfer:

$$
B\left(t_{i}, w_{i}(.), m_{i}(.)\right)=\left\{\left(c_{i}, l_{i}, h_{i}\right) \in X \mid c_{i}+m_{i}\left(h_{i}\right) \leq t_{i}+w_{i}\left(h_{i}\right) l_{i}\right\}
$$

It is important to notice that agents have preferences for human capital so that they may choose a certain level of human capital just because they care about it and not necessarily because this choice is instrumental to the attainment of a higher level of consumption (via a greater productivity).

In order to compare allocations in terms of fairness and efficiency we will use a specific ordering over all the (feasible and not feasible) allocations. It will be denoted by $\bar{R}$ for the weak preferences, with related strict preferences $\bar{P}$ and indifference $\bar{I}$. In other words, $z^{\prime} \bar{R} z$ means that the allocation $z^{\prime}$ is (socially) at least as good as $z, z^{\prime} \bar{P} z$ means that it is strictly better, and $z^{\prime} \bar{I} z$ that they are equivalent. As the social ordering will depend on the profile of the population, we in fact need a social ordering function (SOF), i.e., a mapping from the set of economies to the set of complete orderings over allocations. So, for each $e \in \mathcal{D}$, we write $\bar{R}(e), \bar{P}(e)$, and $\bar{I}(e)$ in order to express the fact that particular social preferences are specific to the economy $e \in \mathcal{D}$. 


\section{From fairness requirements to social welfare}

This section introduces the specific notion of social welfare we use in this paper. Before that let us introduce the two main fairness requirements that single out this specific way of ranking social alternatives.

The need for redistribution comes first of all from the idea that one would like to compensate agents for differences in their circumstances that are beyond their responsibility. In our framework this amounts to saying that inequalities deriving solely from someone's human capital disposition or someone's earning ability are not acceptable. In other words:

It is a strict social improvement to change an allocation by modifying the consumption levels of two agents $i$ and $j$ who have identical preferences $R_{i}=R_{j}$, the same amount of labor time and the same level of human capital, from $c_{i}, c_{j}$ to $c_{i}^{\prime}, c_{j}^{\prime}$ where

$$
c_{i}-\Delta=c_{i}^{\prime}>c_{j}^{\prime}=c_{j}+\Delta
$$

and $\Delta$ is some strictly positive real number.

Redistribution should however have a limit: inequalities solely due to different choices might be acceptable since individuals should, at least to some extent, be held responsible for their goals. If all agents had the same human capital disposition mapping and the same earning ability mapping, then they should be let free to choose a different amount of labor, a different level of human capital and hence, indirectly, a different productivity. The idea that redistribution should not depend on agents' choices pushes in the direction of reducing the inequality of budgets. In a situation where all agents have identical circumstance this amounts to reduce the inequality in lump-sum transfers.

It is a strict social improvement, in a society where all agents have the same circumstances, to change an allocation obtained via lump-sum transfers by modifying the lump-sum transfers of any two agents $i$ and $j$, from $t_{i}, t_{j}$ to $t_{i}^{\prime}, t_{j}^{\prime}$ where

$$
t_{i}-\Delta=t_{i}^{\prime}>t_{j}^{\prime}=t_{j}+\Delta
$$

and $\Delta$ is some strictly positive real number.

Notice that this requirement implies that the laissez-faire allocation (i.e., no redistribution) 
should be the social optimum in this particular case of uniform earning ability and uniform human capital disposition.

The rest of the paper analyzes the consequences of such fairness requirements on the evaluation of policies. In order to do so we rely on a certain notion of social welfare that stems directly from the requirements we have just presented, together with efficiency, informational and robustness requirements. The appendix provides the complete list of the axioms. These axioms single out both a specific measure of individual well-being (i.e., a way to perform interpersonal comparisons) and a way to aggregate these individual measures.

The index of well-being that is obtained is the lump sum transfer that would leave the agent indifferent between her current bundle and being free to choose her labor time and her human capital expenditure from a (hypothetical) budget set where both her earning ability and her human capital disposition are equal to the average ones. More formally, let $\bar{w}()=.\frac{1}{|N|} \sum_{j \in N} w_{j}($.$) and$ $\bar{m}()=.\frac{1}{|N|} \sum_{j \in N} m_{j}($.$) denote respectively the average earning ability function and the average$ human capital disposition function. Then, the implicit transfer associated with an agent's indifference curve, a hypothetical human capital disposition $\bar{m}($.$) , and a hypothetical earning ability \bar{w}($. is defined by ${ }^{8}$

$$
I T_{i}\left(z_{i}, R_{i}, \bar{w}(.), \bar{m}(.)\right)=\left.t \Leftrightarrow z_{i} I_{i} \max \right|_{R_{i}} B(t, \bar{w}(.), \bar{m}(.))
$$

This expression, if considered as a function of $z_{i}$, corresponds (for a given $R_{i}$ ) to a particular moneymetric utility function. This measure of individual well-being does not require any information about individuals' subjective utility, it depends only on ordinal non-comparable preferences.

For any given allocation we can compute the vector of implicit transfers associated with the bundles received by each agent. The level of social welfare is then measured by the lowest implicit transfer in society at such an allocation. Two different allocations will be ranked applying the leximin criterion to the vector of the corresponding implicit transfers.

Average Circumstances Egalitarian Equivalent Leximin $\operatorname{SOF}(\mathrm{ACEE})$. For all $e \in \mathcal{D}$, $z, z^{\prime} \in Z$,

$$
z^{\prime} \bar{R}(e) z \Leftrightarrow\left(I T\left(z_{i}^{\prime}, R_{i}, \bar{w}(.), \bar{m}(.)\right)\right)_{i \in N} \geq_{l e x}\left(I T\left(z_{i}, \bar{w}(.), \bar{m}(.), R_{i}\right)\right)_{i \in N} .
$$

\footnotetext{
${ }^{8}$ The expression $\max \mid{ }_{R_{i}} B(t, \bar{w}(),. \bar{m}()$.$) denotes the subset of B(t, \bar{w}(),. \bar{m}()$.$) that contains the best allocations$ for $R_{i}$. Under our assumptions, this subset is always non-empty.
} 
Let us stress that that the particular reference budget set (the average one) used for the computation of the implicit transfer is, at least to some extent, dictated by the axioms we have used for the characterization. The axioms actually considerably constrain the set of potential options. The natural appeal of using average circumstances as a reference derives from the fact that, ideally, all agents are entitled to an equal split of the overall production possibility set.

Before examining tax implications, let us briefly examine an interesting line of objection to the social objective proposed here. Our approach makes a sharp distinction between individual preferences, which are left to the agents' responsibility, and individual earning abilities and human capital dispositions, for which the objective is full compensation. In practice, it may seem hard to separate abilities and dispositions from preferences. However, insofar as the variables $c$ (net income), $l$ (labor hours), $h$ (education or health status), $m$ (education or medical expenditures), $w$ (hourly wage rate) have an empirical meaning, the approach is applicable. Note that the $m$ function does not make a difference between individuals who need a lot of investment in order to obtain a given level of $h$ because of a genuinely unfavorable disposition or because of ill-will (e.g., laziness in their studies, negligence in following medical guidance). This is similar to the Mirrlees model which does not distinguish between those who have a low wage rate for various reasons. As it is not obvious that individuals should be held liable for apparent "laziness" (which may come from hidden costs), it is probably sensible to err in this charitable direction. On a related issue, our richer model alleviates a criticism that can be raised against the fairness approach in the standard Mirrlees model, namely, that some agents have a great aversion to working due to bad health or access to lower quality jobs, so that it is unfair to let them bear the consequences of this greater aversion. The presence of $h$ in individual preferences in our model makes it possible to account for a greater aversion to work for people with a lower $h$. When an individual is not responsible for her lower $h$, and would be willing to work more with a better $h$, this will show as a disadvantage in the evaluation of her situation. However, there are other constraints on individuals that are still absent from our model (family duties, in particular). 


\section{Tax evaluation}

We will use the notion of social welfare just described, first of all, as a tool for the evaluation of different arbitrary tax policies. As it is well known in the taxation literature since Feldstein [11], the reform problem is often more relevant to policy makers than knowing the features of the optimal tax policy. In such a case the policy maker is primarily interested in determining which part of the tax policy should be changed first in order to obtain a social improvement.

\subsection{Incentive-compatible allocations}

Consider a given economy $e=(R, w(),. m()$.$) . As \bar{w}(),. \bar{m}($.$) are now fixed, for ease of notation we$ write $I T\left(z_{i}, R_{i}\right)$ instead of $I T\left(z_{i}, R_{i}, \bar{w}(),. \bar{m}().\right)$ to denote the implicit transfer of agent $i$ at the bundle $z_{i}$. The policy maker is assumed to know the distribution of types in the population but ignores the characteristics of any particular agent. We assume that, in the second best context, only earned income, $y_{i}=w_{i}\left(h_{i}\right) l_{i}$, and human capital expenditure, $m_{i}=m_{i}\left(h_{i}\right)$, are observable.

A tax policy is a function $T(y, m)$ defining a transfer of income depending on the level of earnings and on the human capital expenditure. The tax turns into a subsidy when $T(y, m)<0$. Individuals are free to choose their labor time and their human capital in the budget set modified by the tax function, namely, the set of bundles $(c, l, h) \in X$ such that

$$
c_{i} \leq w_{i}\left(h_{i}\right) l_{i}-m_{i}\left(h_{i}\right)-T\left(w_{i}\left(h_{i}\right) l_{i}, m_{i}\left(h_{i}\right)\right)
$$

Let $B_{i}(T)$ denote this set. In what follows we will focus on the space of consumption, earnings, human capital expenditure where agent's $i$ budget set becomes

$$
c_{i} \leq y_{i}-m_{i}-T\left(y_{i}, m_{i}\right) .
$$

In addition to the budget constraint, every agent is submitted to the constraints $c, m \geq 0$ and $y \leq w_{i}^{*}(m)$, where the function $w_{i}^{*}(m)=w_{i} \circ m_{i}^{-1}(m)$ determines the earning ability that $i$ obtains with any amount of human capital expenditure $m$.

In the laissez-faire, the budget is $c=y-m$. A laissez-faire budget is represented in Figure 1. The part of the plane $c=y-m$ that lies above $c=0$ is the uplifted triangle on the right-hand side of the figure (numbers in parenthesis are the slopes of the lines). The budget upper boundary is the subset of this triangle delineated by the points OABO. Note that the tax cannot affect the

function $w_{i}^{*}(m)$, therefore it cannot change the projection of the curve $\mathrm{AB}$ on the $(y, m)$ subspace 
(this projection is the dotted curve on the figure), but it can change the level of consumption and enable the agent to obtain positive consumption on the left part of the figure. In particular, with subsidies it may become possible for agents to choose a bundle such that $m_{i}>w_{i}\left(\bar{h}_{i}\right)^{9}$.

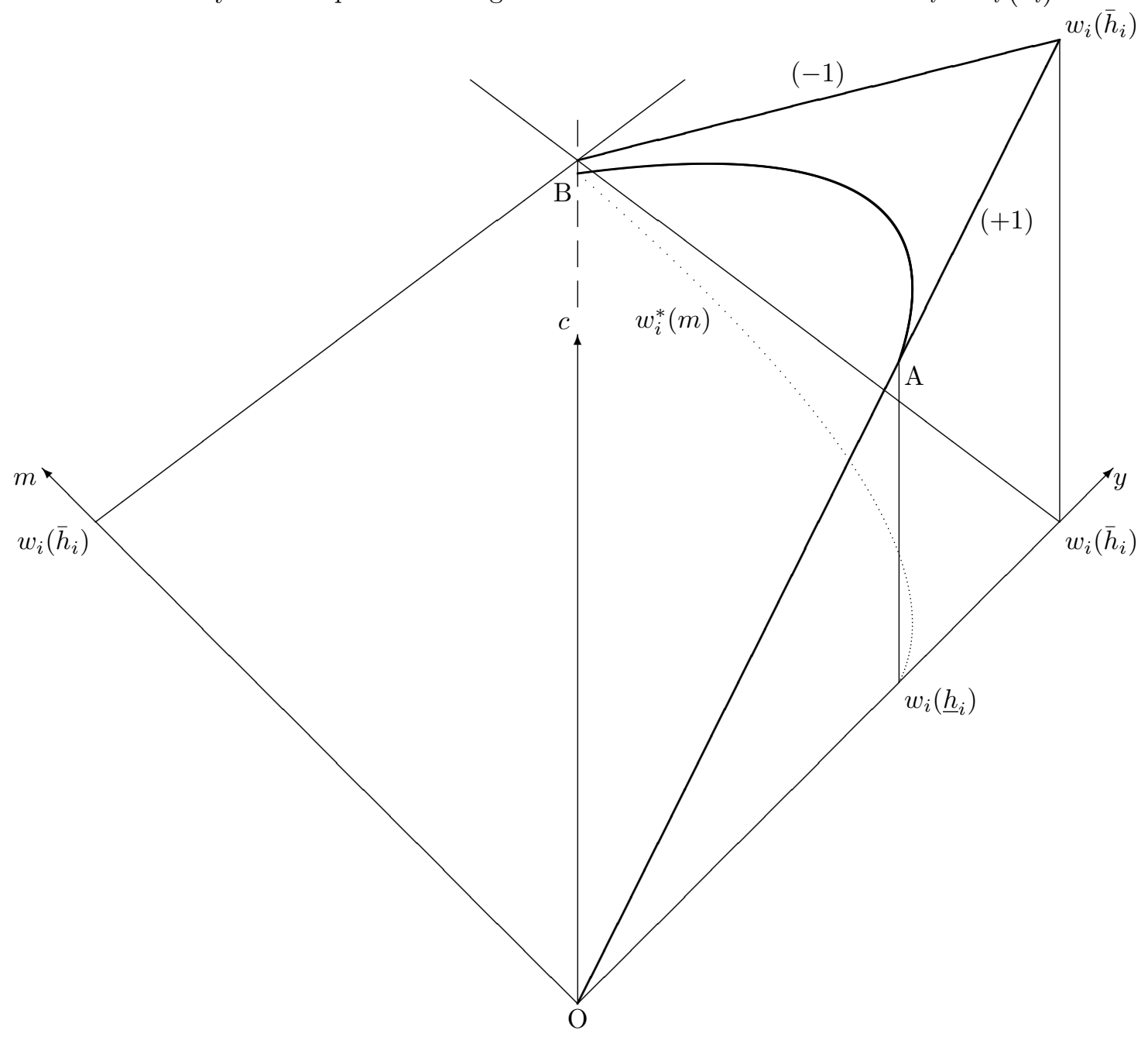

Figure 1: Laissez-faire budget

Let $R_{i}^{*}$ define agent $i$ 's preferences over consumption, earnings and human capital expenditure.

These are derived from the ordinary preferences $R_{i}$ defined in the $(c, l, h)$ space as follows:

$$
(c, y, m) R_{i}^{*}\left(c^{\prime}, y^{\prime}, m^{\prime}\right) \Leftrightarrow\left(c, \frac{y}{w_{i}^{*}(m)}, m_{i}^{-1}(m)\right) R_{i}\left(c^{\prime}, \frac{y^{\prime}}{w_{i}^{*}\left(m^{\prime}\right)}, m_{i}^{-1}\left(m^{\prime}\right)\right) .
$$

These preferences are continuous, convex, increasing in $c$, non-decreasing in $m$, and decreasing in

\footnotetext{
${ }^{9}$ Agents here have preferences over human capital so they might keep acquiring it, provided that their budget set modified by the tax function grants them a positive consumption, even if this does not yield any further improvement in their productivity.
} 
$y$. In addition, they satisfy the following restriction:

$$
(c, y, m) R_{i}^{*}\left(c, y^{\prime}, m^{\prime}\right) \text { if } \frac{y}{w_{i}^{*}(m)} \leq \frac{y^{\prime}}{w_{i}^{*}\left(m^{\prime}\right)} \text { and } m \geq m^{\prime} .
$$

This restriction comes from the fact that in the $(c, l, h)$ space, $(1)$ amounts to

$$
(c, l, h) R_{i}\left(c, l^{\prime}, h^{\prime}\right) \text { if } l \leq l^{\prime} \text { and } h \geq h^{\prime},
$$

which is a direct consequence of monotonicity of preferences in $l$ and $h .{ }^{10}$

The restriction described by (1) has important consequences on the agents' behavior which will significantly affect our analysis. Agents will never choose a bundle $(c, y, m)$ if they are given the possibility to choose another bundle which entails the same labor supply $y / w^{*}(m)$, a greater $m$ (therefore greater $h$ ), and no lower $c$. It is important to stress that an agent might be confronted with this kind of choice in many ordinary situations. For instance, in the laissez-faire budget set where $T(y, m) \equiv 0$, the bundle $\left(w^{*}(m)-m, w^{*}(m), m\right)$, corresponding to working full time and spending $m$ in human capital, is dominated by another bundle $\left(w^{*}\left(m^{\prime}\right)-m^{\prime}, w^{*}\left(m^{\prime}\right), m^{\prime}\right)$ if $m^{\prime}>m$ and $w^{*}\left(m^{\prime}\right)-m^{\prime} \geq w^{*}(m)-m$. In such a situation the extra human capital expenditure is more than repaid by the extra earnings it makes possible: $w^{*}\left(m^{\prime}\right)-w^{*}(m) \geq m^{\prime}-m$. This restriction is a clear consequence of the fact that we are assuming endogenous productivity and imposes quite important changes in the analysis compared to the simpler model in which productivity is exogenous.

In order to better understand how this restriction affects the way people make choices on their budget set let us focus on the example depicted in Figure 2. Consider again the laissezfaire budget already introduced. Let us consider all the pairs $(c, m)$ that are attainable by some agent $i \in N$ for a given amount of labor time $(l=0.5$ in the figure). This locus of points is represented by the (dotted) curve $C D$. In order to better show how this curve evolves we also draw the projection of it on the $(c, m)$ space, i.e., curve $C^{\prime} D^{\prime}$ in the figure. There is a part of the $C^{\prime} D^{\prime}$ curve along which $c$ is increasing in $m$. This means that there is a corresponding part of $C D$ where consumption is increasing in health expenditure (for a given $l$ ). Along this path agent $i$ can increase her consumption just by increasing her human capital (and working the same amount

\footnotetext{
${ }^{10} \mathrm{An}$ additional restriction is that

$$
(c, y, m) I_{i}^{*}\left(c, y, m^{\prime}\right) \text { if } m, m^{\prime} \geq m_{i}\left(\bar{h}_{i}\right)
$$
}

because this corresponds to a situation in which the corresponding $(c, l, h)$ bundles are the same. 
of time) because the extra amount of money devoted to human capital is more than repaid by the productivity increase. Hence, the increasing part of $C D$ will never be chosen by the agent, whatever her preferences. Finally, one should also notice that agent $i$ might still choose a point on the decreasing part of $C D$ : she could be willing, given her preferences, to give away consumption in order to acquire a higher amount of human capital.

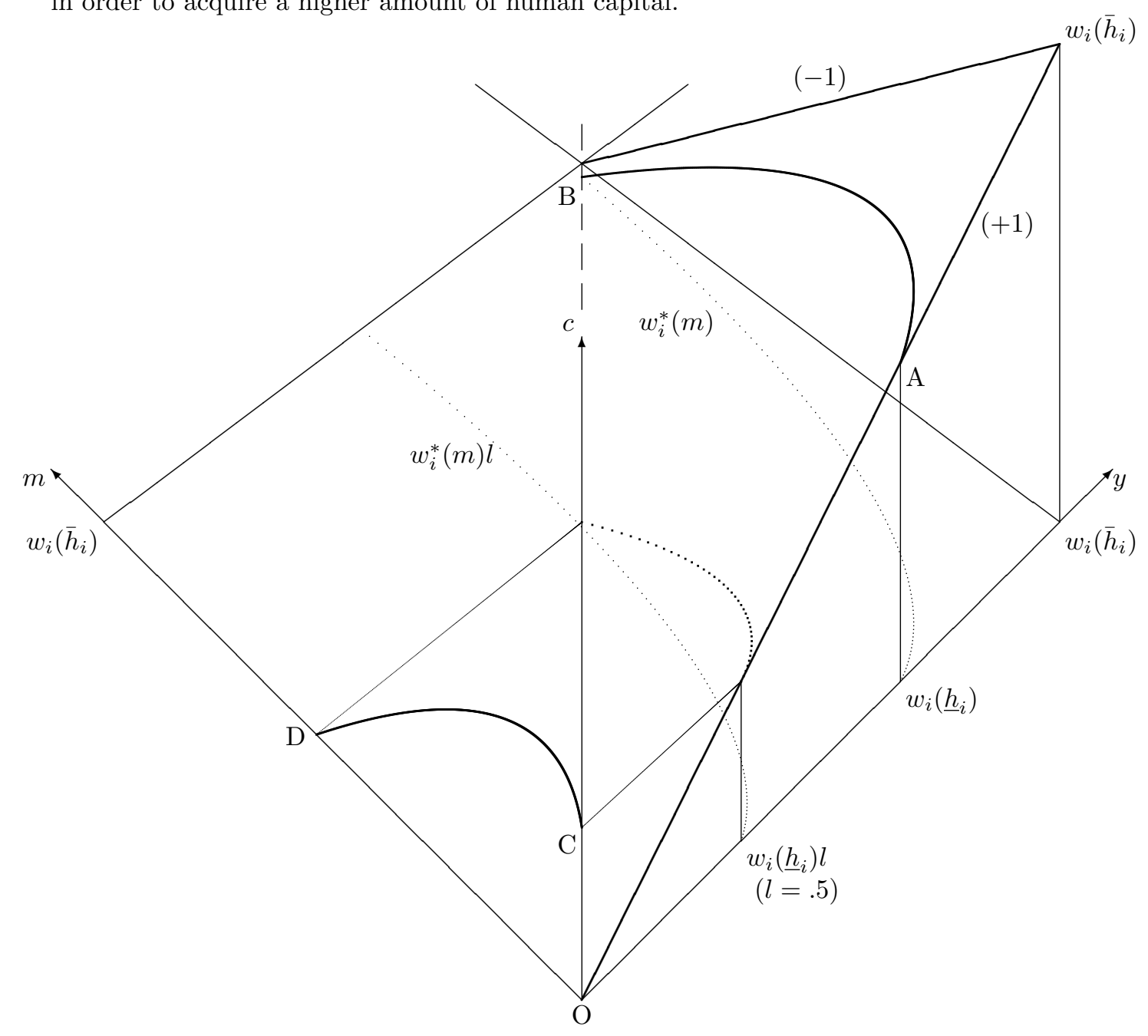

Figure 2: Budget curve in $(c, m)$ space for fixed $l$

An allocation $z \in Z$ is incentive compatible if and only if no agent envies the bundle of any other agent provided that such a bundle is feasible for her: for all $i, j \in N$,

$$
\left(c_{i}, y_{i}, m_{i}\right) R_{i}^{*}\left(c_{j}, y_{j}, m_{j}\right) \text { or } y_{j}>w_{i}^{*}\left(m_{i}\right) .
$$

In other words agent $i$ has to receive an allocation that she prefers to the allocation received by agent $j$ unless it is not possible for her to mimic agent $j$. This implies that any incentive- 
compatible allocation can be obtained by letting every agent $i \in N$ choose her best bundle, under the constraint $y \leq w_{i}^{*}(m)$, in a budget set modified by a well chosen tax function $T(y, m)$ such that the locus of points

$$
S(T)=\left\{(c, y, m) \in \mathbb{R}_{+}^{3} \mid c \leq y-m-T(y, m)\right\},
$$

lies nowhere above the envelope curve of the indifference curves in the $(c, y, m)$ space, and intersects this envelope curve at all points $\left(c_{i}, y_{i}, m_{i}\right)$ for each $i \in N$. Conversely, any allocation obtained by letting all agents choose from a budget set $S(T)$, under the constraint, $y \leq w_{i}^{*}(m)$, is incentive compatible. In other words, the taxation principle (Guesnerie [22], Rochet [35] ) holds in this model. An incentive compatible allocation so obtained is feasible if and only if $\sum_{i=1}^{N} T\left(y_{i}, m_{i}\right) \geq 0$.

For every incentive-compatible allocation, there is a minimal tax that implements it, namely, the tax $T$ such that $y-m-T(y, m)$ follows the lower envelope of agents' upper contour sets in the $(c, y, m)$ space at the allocation. For such a tax, $S(T)$ coincides with the intersection of the closed lower contour sets of the agents.

It is worth mentioning that minimal taxes, in this model, form a relatively narrow class of tax functions, because of (1). In the classical Mirrlees model (with exogenous productivities), any non-decreasing function $y-T(y)$ can be arbitrarily close to the lower envelope of agents' upper contour sets at the allocation generated by the tax function for a sufficiently large population with sufficiently diverse preferences. In contrast, in this model, a function $y-m-T(y, m)$ that is non-decreasing in $y$ and non-increasing in $m$ may never be close to a minimal tax configuration. Let us develop this point. It holds true, by monotonicity of preferences $R_{i}^{*}$, that we can restrict attention to tax functions $T$ such that $y-m-T(y, m)$ is non-decreasing in $y$ and non-increasing in $m$. But the restriction (1) implies that some parts of such a budget set may never be chosen by any agent. Take a bundle $(c, y, m)$ from the budget frontier such that for all $i \in N$, the expression

$$
\frac{y}{w_{i}^{*}(m)} w_{i}^{*}(x)-x-T\left(\frac{y}{w_{i}^{*}(m)} w_{i}^{*}(x), x\right)
$$

is increasing in $x$. No agent will choose such a bundle, whatever her preferences, because for a fixed amount of labor $l_{i}=y / w_{i}^{*}(m)$, consumption is increasing with human capital expenditure (one could think of the curve $C D$ in the previous example). 


\subsection{Estimating social welfare}

The evaluation of a policy hinges on its social consequences. It turns out that evaluating the consequences of a certain policy is made possible by the fact that we are using a social ordering function of the leximin type. Indeed, given the allocation generated by a given tax policy we first need to spot the worst-off agent at such an allocation, and this is often sufficient to make the evaluation. Once we have this piece of information we know which part of the budget set modified by the tax function has to be changed (and how) in order to obtain a social improvement.

Let $T$ be an arbitrary tax function such that $y-m-T(y, m)$ is non-decreasing in $y$ and non-increasing in $m$. The main purpose of this section (and the following one) is to provide a measure of $\min _{i} I T\left(z_{i}, R_{i}\right)$ at the allocation $z$ generated by $T$.

Let us first consider, for expositional purposes, the budget set, modified by the tax function $T$, of some agent $i \in N$ in the $(c, l, h)$ space. As explained above, the upper frontier of $B_{i}(T)$ may contain dominated parts (in terms of consumption). Indeed, increasing $h$ may entail an increase in productivity that pays more than its cost. It is therefore better to focus on the undominated parts of the budget set since this gives a more accurate picture of the well-being opportunities of the worst type. More precisely, let us define a new budget set which flattens the dominated parts of $B_{i}(T)$. For an arbitrary function $f(h)$, let $f^{+}(h)$ be the lowest non-increasing cover of $f$, i.e., the lowest function that is non-increasing and never below $f$. For a given $l \in[0,1]$ and $T$, let

$$
b_{i l T}(h)=w_{i}(h) l-m_{i}(h)-T\left(w_{i}(h) l, m_{i}(h)\right) .
$$

In order to construct the new budget set, for any $l \in[0,1]$ we will only consider the couples $(c, h)$ such that

$$
c \leq b_{i l T}^{+}(h) .
$$

This step is exemplified in figure 3 where the thin line depicts, for a given $l$, the increasing part of $b_{i l T}(h)$ and the thick line depicts $b_{i l T}^{+}(h)$.

For any $i \in N$, let $B_{i}^{+}(T)$ denote the budget set obtained from $B_{i}(T)$ using, for any $l \in[0,1]$, such construction. Let also $B_{\cap}^{+}(T)=\bigcap_{i \in N} B_{i}^{+}(T)$.

Finally, consider the budget $B\left(t_{0}, \bar{w}(),. \bar{m}().\right)$ of the average type that would be obtained under laissez-faire but with a lump-sum transfer $t_{0} \in \mathbb{R}$ :

$$
c \leq \bar{w}(h) l-\bar{m}(h)+t_{0},
$$




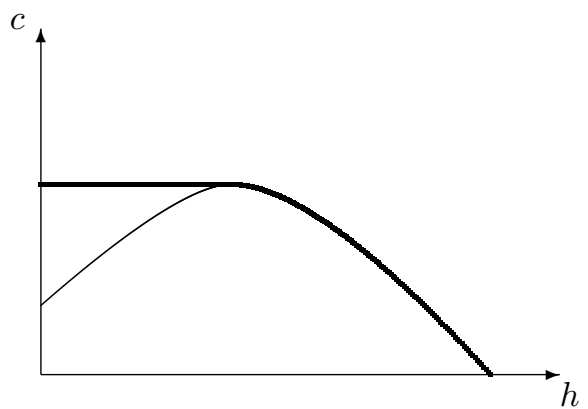

Figure 3: Budget set for given $l$

namely, the hypothetical budget set used by our social welfare function to measure individual well being. For $t_{0}$ small enough (possibly negative), this budget $B\left(t_{0}, \bar{w}(),. \bar{m}().\right)$ is contained in $B_{\cap}^{+}(T)$. Let $t_{0}^{*}$ be the maximum level at which this property is satisfied (as exemplified in figure 4 for some $l \in[0,1])$. This maximum level is well defined because both $B_{\cap}^{+}(T)$ and $B\left(t_{0}^{*}, \bar{w}(),. \bar{m}().\right)$ are compact, and the latter varies continuously with $t_{0}$.

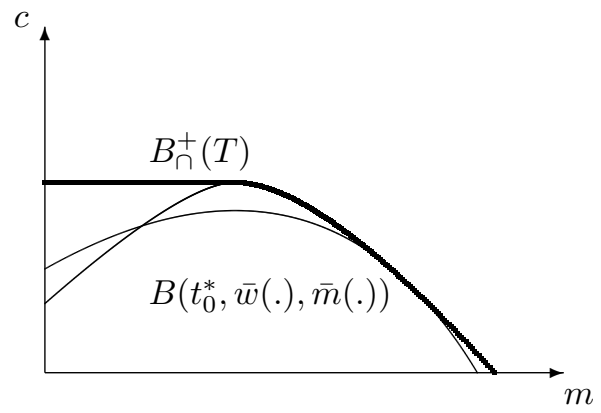

Figure 4: Budget tangency for some $l$

Agents, given their preferences, choose their bundle on the budget set modified by the tax function (see the indifference curves depicted in figure 5). Clearly the indifference surface passing through each bundle lies always above such a budget set. Moreover, no agent will choose a bundle that is in the interior of $B_{\cap}^{+}(T)$ so that, by construction, the allocation generated by the tax function $T$ will grant to any agent a level of well-being no lower than $t_{0}^{*}$. This observation enables us to bracket the value of $\min _{i} I T\left(z_{i}, R_{i}\right)$, as stated below. Observe on the figures that the boundary of $B\left(t_{0}^{*}, \bar{w}(),. \bar{m}().\right)$ crosses the non-flattened part of $B_{\cap}^{+}(T)$ (i.e., $B_{i}(T)$ ). This explains why it is important to work with $B_{i}^{+}(T)$ rather than $B_{i}(T)$ in order to obtain a tighter lower bound 


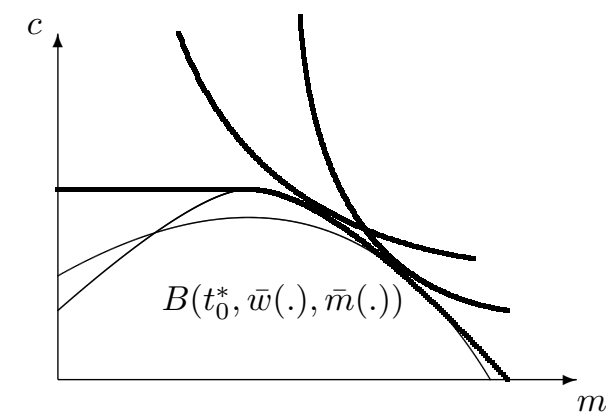

Figure 5: Individuals choosing a particular $l$

Proposition 1 Let $z$ be an incentive-compatible allocation generated by the tax function T. Then

$$
t_{0}^{*} \leq \min _{i} I T\left(z_{i}, R_{i}\right)
$$

Proof. By construction, for all $i \in N$,

$$
B\left(t_{0}^{*}, \bar{w}(.), \bar{m}(.)\right) \subseteq B_{\cap}^{+}(T) \subseteq B_{i}^{+}(T) .
$$

Moreover, for all $i \in N$, the indifference surface passing through $z_{i}$ lies always (weakly) above $B_{i}^{+}(T)$, therefore (weakly) above $B\left(t_{0}^{*}, \bar{w}(),. \bar{m}().\right)$. Then, necessarily, $t_{0}^{*} \leq I T\left(z_{i}, R_{i}\right)$ for all $i \in N$.

Proposition 1 only provides a lower bound for $\min _{i} I T\left(z_{i}, R_{i}\right)$. We now describe a situation in which it is an exact measure of $\min _{i} I T\left(z_{i}, R_{i}\right)$. In the next subsections, an analysis of the sort of bundles that correspond to the lower bound is provided, and an upper bound is provided.

In order to find a situation in which $t_{0}^{*}=\min _{i} I T\left(z_{i}, R_{i}\right)$, it is convenient to refer to the literature on fair income tax in the Mirrlees model, as summarized in Fleurbaey and Maniquet [18]. In the Mirrlees model the most disadvantaged individuals are those with the smallest (exogenous) earning ability, indeed they have the smallest opportunity set. In our framework this amounts to introducing the assumption that there is a worst type, in terms of circumstances, in the population profile, i.e., a set of poor agents who are uniformly disadvantaged with respect to earning ability and human capital disposition.

Assumption 1 (Worst Type): There is a nonempty subset $P \subset N$ and two functions $\underline{w}(),. \underline{m}($.$) , such that for all i \in P$, all $j \in N, w_{i}(h)=\underline{w}(h) \leq w_{j}(h)$ and $m_{i}(h)=\underline{m}(h) \geq m_{j}(h)$ for all $h$. 
This assumption implies in particular that $\underline{w}(h) \leq \bar{w}(h)$ and $\underline{m}(h) \geq \bar{m}(h)$ and it simplifies the analysis because it enables us to identify the worst-off agents more easily. Notice that, for every $i \in N$,

$$
w_{i}(h) l-m_{i}(h)-T\left(w_{i}(h) l, m_{i}(h)\right) \geq \underline{w}(h) l-\underline{m}(h)-T(\underline{w}(h) l, \underline{m}(h)),
$$

because the expression $w l-m-T(w l, m)$ is non-decreasing in $w$ and non-increasing in $m$. This means that the worst type has a budget set that is always included in the budget sets of all other types of agents. For $i \in P$, the budget $B_{i}^{+}(T)$ will be denoted $\underline{B}^{+}(T)$. For every $i \in N$, $B_{i}^{+}(T)$ includes $\underline{B}^{+}(T)$ because whenever for two arbitrary functions $f$ and $g$ one has $f \geq g$, then necessarily $f^{+} \geq g^{+}$. Therefore $\underline{B}^{+}(T)=B_{\cap}^{+}(T)$.

In order to obtain that the lower bound expressed in Proposition 1 coincides with the wellbeing level of the worst-off agent one also needs another assumption (introduced by Fleurbaey and Maniquet [16]). It requires that whenever an individual is willing to choose a bundle that is accessible to the worst type, there is an agent of the worst type who is willing to choose the same bundle.

Assumption 2 (Preference Diversity): For all $i \in N$, there exists $j \in P$ such that $R_{j}^{*}=$ $\left.R_{i}^{*}\right|_{\left\{(c, y, m) \mid y \leq \underline{w}^{*}(m)\right\}}$.

This assumption is easier to satisfy with a large population (there must be as many sorts of preferences $R_{i}^{*}$ in $P$ as there are in the rest of the population), though it may be satisfied with a finite number of agents. Note that, in our framework, this assumption may impose restrictions on agents' preferences, because their indifference surfaces must not contain dominated areas for $P$ agents, i.e., there must not exist $x, x^{\prime}$ such that $x R_{i}^{*} x^{\prime}$ for some $i \in N$ and $x^{\prime}$ dominates $x$ for any $j \in P$ (in the sense that $x^{\prime}$ involves greater consumption, leisure, human capital). ${ }^{11}$ When the $w^{*}($.$) functions for all types are proportional to one another, however, this possibility vanishes.$ Indeed, if $x^{\prime}=\left(c^{\prime}, y^{\prime}, m^{\prime}\right)$ dominates $x=(c, y, m)$ for some $j \in P$, this means that

$$
\left(c^{\prime},-\frac{y^{\prime}}{\underline{w}^{*}\left(m^{\prime}\right)}, m^{\prime}\right)>\left(c,-\frac{y}{\underline{w}^{*}(m)}, m\right) .
$$

\footnotetext{
${ }^{11}$ To put it differently, there might be parts of the budget set that will never be chosen by $P$ agents because of (1) but, at the same time, there might be agents in $N \backslash P$ that, given their preferences, would be willing to choose a bundle in such parts. Imposing Preference Diversity would rule out this situation.
} 
For $i \in N \backslash P$ such that $w_{i}^{*}=\lambda \underline{w}^{*}$, with $\lambda>1$, this implies

$$
\left(c^{\prime},-\frac{y^{\prime}}{w_{i}^{*}\left(m^{\prime}\right)}, m^{\prime}\right)>\left(c,-\frac{y}{w_{i}^{*}(m)}, m\right)
$$

i.e., $x^{\prime}$ dominates $x$ for $i$ as well. Therefore, in this case, Preference Diversity imposes no restriction on the preferences of agents from $N \backslash P$.

The following result is similar to results obtained by Fleurbaey and Maniquet [16],[17].

Corollary 2 Assume Worst Type and Preference Diversity hold. Then for every minimal tax $T$ one has $\min _{i} I T\left(z_{i}, R_{i}\right)=t_{0}^{*}$.

Proof. By Preference Diversity, the lower envelope of upper contour sets of all $i \in N$, for bundles satisfying $y \leq \underline{w}^{*}(m)$, coincides with the lower envelope of upper contour sets of all $i \in P$. By construction, the lower envelope of upper contour sets for all $i \in P$ contains no dominated part. Moreover, the fact that $T$ is minimal implies that the budget frontier coincides with the lower envelope of upper contour sets for all $i \in N$. For bundles such that $y \leq \underline{w}^{*}(m)$, the budget frontier therefore coincides with the lower envelope of upper contour sets for all $i \in P$. This implies that $\underline{B}^{+}(T)=B_{i}(T)$ for any $i \in P$, otherwise there would be a gap between the budget frontier and the lower envelope of upper contour sets. Therefore the intersection of the upper frontier of $B\left(t_{0}^{*}, \bar{w}(),. \bar{m}().\right)$ with the upper frontier of $\underline{B}^{+}(T)$ belongs to the upper contour set of some $i \in P$, which implies that for this particular $i, I T\left(z_{i}, R_{i}\right)=t_{0}^{*}$. By Proposition 1, necessarily $\min _{i \in N} \operatorname{IT}\left(z_{i}, R_{i}\right)=t_{0}^{*}$.

The fact that, due to (1), both the Preference Diversity assumption and the minimality assumption are rather special in our framework restricts the scope of Corollary 2, in contrast with the Mirrlees model in which they are unexceptional. In the framework of this paper, it is then harder to spot precisely the worst-off agents at arbitrary tax policies. In what follows however we show that under some reasonable assumptions it is still possible to define the area of the budget set modified by the tax function that should be the primary focus of a reform.

\subsection{More on the lower bound}

In the previous subsection its computation of $t_{0}^{*}$ is performed in the $(c, l, h)$ space and it is not transparently connected with the tax function $T$. It is instructive to examine how $t_{0}^{*}$ can be computed when one looks at the budget set modified by the tax function in the $(c, y, m)$ space. 
We retain the Worst Type assumption in the sequel, as it allows us to focus on the low incomes $y \leq \underline{w}^{*}(m)$. Moreover, the Worst Type assumption has an immediate consequence when it comes to the computation of $t_{0}^{*}$, because it shifts the focus on $\underline{B}^{+}(T)$ since, as mentioned earlier, $\underline{B}^{+}(T)=$ $B_{\cap}^{+}(T)$. Hence, the first thing to do in order to obtain a translation of $t_{0}^{*}$ in the $(c, y, m)$ space is to locate $\underline{B}^{+}(T)$ in the $(c, y, m)$ space.

In the $(c, l, h)$ space, the basic element used for the construction of $\underline{B}^{+}(T)$ is, for any $l \in[0,1]$, the subset described by the inequality

$$
c \leq \underline{b}_{l T}(h),
$$

where $\underline{b}_{l T}(h)$ denotes $b_{i l T}(h)$ for any $i \in P$. This whole expression can be rewritten as a function of $m$ if one replaces $w_{i}(h)$ with $w_{i}^{*}(m)$ in $b_{i l T}(h)$. In particular, let $\underline{w}^{*}(m)$ denote $w_{i}^{*}(m)$ for any $i \in P$. Equation (3) then can be rewritten as

$$
c \leq \underline{b}_{l T}^{*}(m)=\underline{w}^{*}(m) l-m-T\left(\underline{w}^{*}(m) l, m\right),
$$

(this curve could be exemplified by the line CD in Figure 2). As in the previous section let $\underline{b}_{l T}^{*+}$ denote the lowest non-increasing cover of $\underline{b}_{l T}^{*}$. In order to complete the transposition of the budget $c \leq \underline{b}_{l T}^{*+}(h)$ into the $(c, y, m)$ space one has simply to set $l=y / \underline{w}^{*}(m)$ and require $y \leq \underline{w}^{*}(m)$. The relevant budget is then

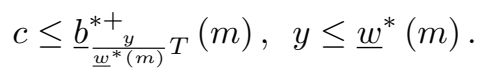

The other element needed for the computation of $t_{0}^{*}$ is the set $B\left(t_{0}, \bar{w}(),. \bar{m}().\right)$, that represents the budget set of a hypothetical agent with average circumstances who receives a lump sum transfer $t_{0}$. This set is defined in the $(c, l, h)$ space by

$$
c \leq \bar{w}(h) l-\bar{m}(h)+t_{0}
$$

which corresponds in the $(c, y, m)$ space to

$$
c \leq y-m+t_{0} \text { and } y \leq \bar{w}^{*}(m),
$$

where $\bar{w}^{*}(m)=\bar{w}\left(\bar{m}^{-1}(m)\right) \cdot{ }^{12}$

In order to seek the intersection between $B\left(t_{0}, \bar{w}(),. \bar{m}().\right)$ and $\underline{B}^{+}(T)$ in the $(c, y, m)$ space, the former budget has to be properly rescaled so as to fit the set of bundles that are actually attainable by a poor agent. This is done as follows. Take any point $(c, y, m)$ that is attainable

\footnotetext{
${ }^{12}$ Notice that this is not generally the same as $\frac{1}{n} \sum_{i} w_{i}^{*}(m)$.
} 
by a worst-type agent, i.e., such that $y \leq \underline{w}^{*}(m)$. This point corresponds to some point $(c, l, h)$ such that $c=c, l=y / \underline{w}^{*}(m), h=\underline{m}^{-1}(m)$. This point $(c, l, h)$ would also correspond in the $(c, y, m)$ space, for a an agent with average circumstances, to some point $\left(c^{\prime}, y^{\prime}, m^{\prime}\right)$ such that $c^{\prime}=c, y^{\prime}=\bar{w}(h) l, m^{\prime}=\bar{m}(h)$.Hence we obtain the transformation

$$
\begin{aligned}
c^{\prime} & =c \\
y^{\prime} & =\bar{w}\left(\underline{m}^{-1}(m)\right) y / \underline{w}^{*}(m) \\
m^{\prime} & =\bar{m} \circ \underline{m}^{-1}(m) .
\end{aligned}
$$

Therefore, in the $(c, y, m)$ space, the budget $B\left(t_{0}, \bar{w}(),. \bar{m}().\right)$, as it appears to a worst-type agent, is rescaled to

$$
c \leq \frac{\bar{w} \circ \underline{m}^{-1}(m)}{\underline{w}^{*}(m)} y-\bar{m} \circ \underline{m}^{-1}(m)+t_{0} .
$$

Finally consider any intersection point $\left(c^{\prime \prime}, y^{\prime \prime}, m^{\prime \prime}\right)$ between $B\left(t_{0}, \bar{w}(),. \bar{m}().\right)$ and $\underline{B}^{+}(T)$. For

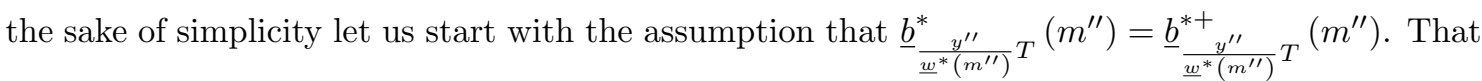
is, the intersection does not occur in a dominated part of the budget $\underline{B}(T)$. Then we have

$$
y^{\prime \prime} \frac{\bar{w} \circ{\underline{m^{\prime \prime}}}^{-1}\left(m^{\prime \prime}\right)}{\underline{w}^{*}\left(m^{\prime \prime}\right)}-\bar{m} \circ \underline{m}^{-1}\left(m^{\prime \prime}\right)+t_{0}=y^{\prime \prime}-m^{\prime \prime}-T\left(y^{\prime \prime}, m^{\prime \prime}\right)
$$

implying

$$
t_{0}=y^{\prime \prime}\left[1-\frac{\bar{w} \circ \underline{m}^{-1}\left(m^{\prime \prime}\right)}{\underline{w}^{*}\left(m^{\prime \prime}\right)}\right]+\bar{m} \circ \underline{m}^{-1}\left(m^{\prime \prime}\right)-m^{\prime \prime}-T\left(y^{\prime \prime}, m^{\prime \prime}\right) .
$$

The value of $t_{0}^{*}$ corresponds to the minimum of this expression, i.e., the lowest value of $t_{0}$ such that the upper boundaries of the two budget sets have a non-empty intersection.

Proposition 3 Assume Worst Type holds. Let $\left(c^{\prime \prime}, y^{\prime \prime}, m^{\prime \prime}\right)$ denote any intersection point between

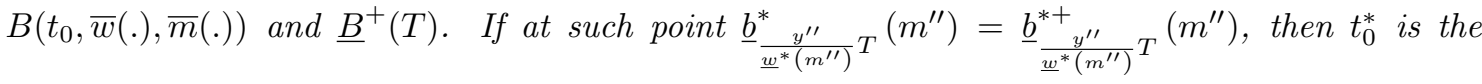
minimum of

$$
y^{\prime \prime}\left[1-\frac{\bar{w}_{N} \circ \underline{m}^{-1}\left(m^{\prime \prime}\right)}{\underline{w}^{*}\left(m^{\prime \prime}\right)}\right]+\bar{m}_{N} \circ \underline{m}^{-1}\left(m^{\prime \prime}\right)-m^{\prime \prime}-T\left(y^{\prime \prime}, m^{\prime \prime}\right) .
$$

Otherwise, the minimum of (4) is less or equal to $t_{0}^{*}$, and therefore still provides a lower bound for $\min _{i} \operatorname{IT}\left(z_{i}, R_{i}\right)$.

Proof. The first part has been proved in the text.

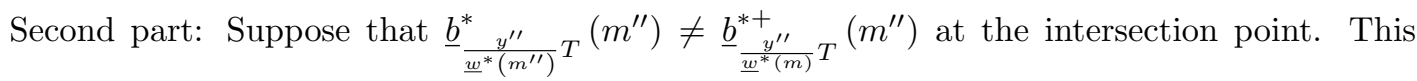
means that the intersection between $B\left(t_{0}, \bar{w}(),. \bar{m}().\right)$ and $\underline{B}^{+}(T)$ occurs for a greater $t_{0}$ than 
the intersection between $B\left(t_{0}, \bar{w}(),. \bar{m}().\right)$ and $\underline{B}(T)$. The minimum of (4) gives $t_{0}$ for the latter intersection.

It is worth examining further how (4) can be used to compute $t_{0}^{*}$. Let us focus on the particular case in which $T$ is non-decreasing in $y$. Then the expression (4) is decreasing in $y^{\prime \prime}$ so that necessarily $y^{\prime \prime}=\underline{w}^{*}\left(m^{\prime \prime}\right)$. Let us substitute $\underline{w}^{*}\left(m^{\prime \prime}\right)$ for $y^{\prime \prime}$ in (4); this yields:

$$
\underline{w}^{*}\left(m^{\prime \prime}\right)-m^{\prime \prime}-T\left(\underline{w}^{*}\left(m^{\prime \prime}\right), m^{\prime \prime}\right)+\bar{m} \circ \underline{m}^{-1}\left(m^{\prime \prime}\right)-\bar{w} \circ \underline{m}^{-1}\left(m^{\prime \prime}\right) .
$$

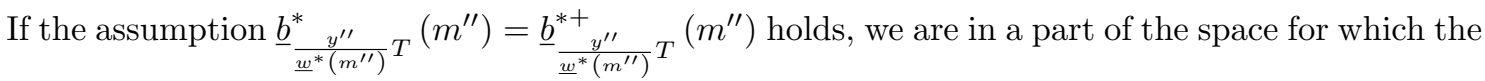
first part of equation (5), $\underline{w}^{*}\left(m^{\prime \prime}\right)-m^{\prime \prime}-T\left(\underline{w}^{*}\left(m^{\prime \prime}\right), m^{\prime \prime}\right)$, is non-increasing in $m^{\prime \prime}$. The behavior of the remaining part of $(5), \bar{m} \circ \underline{m}^{-1}\left(m^{\prime \prime}\right)-\bar{w} \circ \underline{m}^{-1}\left(m^{\prime \prime}\right)$, is less obvious, as it may decrease for low $m^{\prime \prime}$

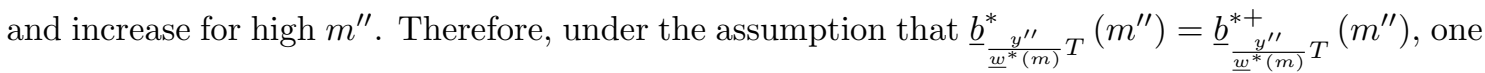
has to consider two possible alternatives. Either the minimum is obtained for some $m^{\prime \prime}$ satisfying $\underline{w}^{*}\left(m^{\prime \prime}\right)-m^{\prime \prime}-T\left(\underline{w}^{*}\left(m^{\prime \prime}\right), m^{\prime \prime}\right)>0$ and

$$
\left(1-T_{y}\left(\underline{w}^{*}\left(m^{\prime \prime}\right), m^{\prime \prime}\right)\right) \underline{w}^{* \prime}\left(m^{\prime \prime}\right)-T_{m}\left(\underline{w}^{*}\left(m^{\prime \prime}\right), m^{\prime \prime}\right)-1=\frac{\bar{w}^{\prime} \circ \underline{m}^{-1}\left(m^{\prime \prime}\right)-\bar{m}^{\prime} \circ \underline{m}^{-1}\left(m^{\prime \prime}\right)}{\underline{m}^{\prime} \circ \underline{m}^{-1}\left(m^{\prime \prime}\right)},
$$

(interior solution) where $T_{x}$ denotes the partial derivative of $T$ with respect to $x$ (assuming that these functions are differentiable), or

$$
t_{0}^{*}=-\bar{w} \circ \underline{m}^{-1}\left(m^{\prime \prime}\right)+\bar{m} \circ \underline{m}^{-1}\left(m^{\prime \prime}\right)
$$

for $m^{\prime \prime}$ such that $\underline{w}^{*}\left(m^{\prime \prime}\right)-m^{\prime \prime}-T\left(\underline{w}^{*}\left(m^{\prime \prime}\right), m^{\prime \prime}\right)=0$ (corner solution).

Let us interpret these results, in light of the fact that the intersection of the two budget sets identifies the worst-off agent if there is $i \in P$ whose upper contour set contains this point. The left hand side of equation (6) features the impact of an increase in $m^{\prime \prime}$ on consumption for an agent from $P$. On the right-hand side, it displays the impact on consumption, of the same increase in human capital, for an agent with average characteristics at laissez-faire. Hence, the worst-off agent, if her bundle lies at the intersection, belongs to $P$, works full time and enjoys a post-tax productivity of human capital expenditures equal to the pre-tax productivity of an average type agent with the same amount of labor and human capital (note that the same level of $h$ would be obtained by the average type agent for a different level of $m$ ). The second case, equation (7), is obtained when the intersection of the two budget sets occurs at a bundle where consumption is null (a corner solution). This corresponds to a case in which the worst-off situation corresponds to the greatest affordable human capital expenditure (and full-time work) for a worst-type agent. 


\subsection{An upper bound}

Let us now seek an upper bound for $\min _{i} I T\left(z_{i}, R_{i}\right)$. From the definition of $I T\left(z_{i}, R_{i}\right)$, for each $i \in N$, at the allocation $z$,

$$
I T\left(z_{i}, R_{i}\right) \leq c_{i}-\bar{w}\left(h_{i}\right) l_{i}+\bar{m}\left(h_{i}\right)
$$

The right-hand side of this inequality is, for $i \in N$, equal to

$$
c_{i}-\frac{\bar{w} \circ m_{i}^{-1}\left(m_{i}\right)}{w_{i}^{*}\left(m_{i}\right)} y_{i}+\bar{m} \circ m_{i}^{-1}\left(m_{i}\right),
$$

so that

$$
\min _{i} I T\left(z_{i}, R_{i}\right) \leq \min _{i \in N}\left[c_{i}-\frac{\bar{w} \circ m_{i}^{-1}\left(m_{i}\right)}{w_{i}^{*}\left(m_{i}\right)} y_{i}+\bar{m} \circ m_{i}^{-1}\left(m_{i}\right)\right] .
$$

This term is not an interesting upper bound because it requires the computation of the bundle of all types of agents induced by $T$. This is almost the same information as is needed to compute the actual distribution of $I T\left(z_{i}, R_{i}\right)$ — the only information that is not needed is the indifference sets at each bundle.

In order to reduce the computational requirements of the upper bound, one can invoke Preference Diversity and then look only at all $i$ such that $y_{i} \leq \underline{w}^{*}\left(m_{i}\right)$. Moreover, knowing the distribution of earnings and human capital expenditures in this low-income bracket is enough, and no information about which type consumes which bundle is needed. However, as we have already explained, this assumption imposes restrictions on the admissible profiles of preferences.

An alternative is to focus on the undominated parts of the budget set and assume that, at least locally, preferences are sufficiently diverse. More formally, one could look at all $i$ such that

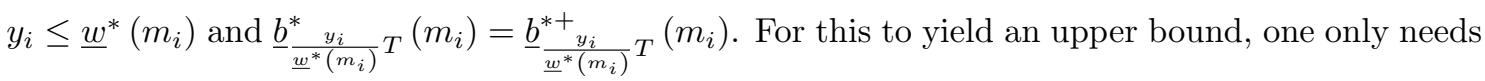
to assume that all points $\left(c_{i}, y_{i}, m_{i}\right)$ such that $\left(y_{i}, m_{i}\right)$ satisfy these conditions could be chosen by some agents from $P$ (they can also be chosen by some other agent). This is formulated in the following assumption.

Assumption 3 (Weak Preference Diversity): For all $i \in N$, if $y_{i} \leq \underline{w}^{*}\left(m_{i}\right)$ and

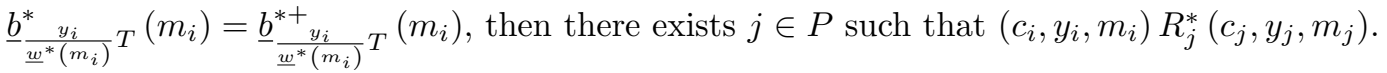

Note that by incentive compatibility, necessarily $\left(c_{j}, y_{j}, m_{j}\right) R_{j}^{*}\left(c_{i}, y_{i}, m_{i}\right)$, so that we could as well write $\left(c_{i}, y_{i}, m_{i}\right) I_{j}^{*}\left(c_{j}, y_{j}, m_{j}\right)$ in the assumption . Assumption 3 is a logically weaker variant of the Preference Diversity assumption. Indeed it only assumes that, for the particular tax function 
$T$, and the particular allocation it generates, the undominated part of the budget set of agents in $P$ contains no bundle that is chosen by some agent with better circumstances and would not be acceptable to any of the agents in $P$. This is weaker than Preference Diversity in two ways. First, it depends on the specific tax function $T$, and it may not hold for some other tax function, whereas Preference Diversity is independent of $T$. Second, unlike Preference Diversity, it imposes no restriction on the preferences of agents in $N \backslash P$. In a nutshell, our new assumption is much weaker, and obtains results for more economies, but it does not apply to all tax functions.

Under such assumptions one obtains an upper bound that requires only knowing the worst and average functions $w$ and $m$.

Proposition 4 Assume Worst Type holds. Let $z$ be an incentive-compatible allocation generated by the tax function T. Under Preference Diversity,

$$
\min _{i} \operatorname{IT}\left(z_{i}, R_{i}\right) \leq \min _{i: y_{i} \leq \underline{w}^{*}\left(m_{i}\right)}\left[c_{i}-\frac{\bar{w} \circ \underline{m}^{-1}\left(m_{i}\right)}{\underline{w}^{*}\left(m_{i}\right)} y_{i}+\bar{m} \circ \underline{m}^{-1}\left(m_{i}\right)\right] .
$$

Under Weak Preference Diversity,

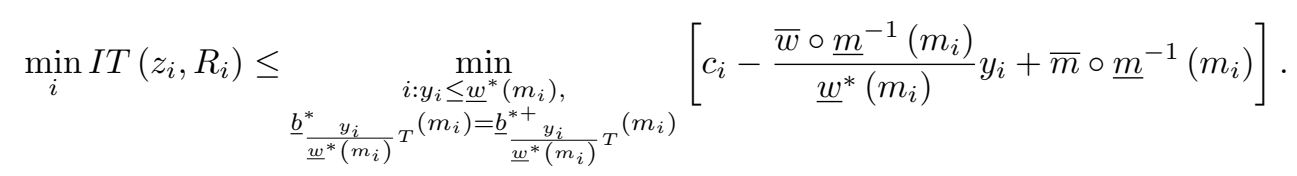

Proof. First, observe that, for the $P$ subpopulation defined by the Worst Type assumption,

$$
\begin{aligned}
\min _{i \in P}\left[c_{i}-\frac{\bar{w} \circ \underline{m}^{-1}\left(m_{i}\right)}{\underline{w}^{*}\left(m_{i}\right)} y_{i}+\bar{m} \circ \underline{m}^{-1}\left(m_{i}\right)\right] & =\min _{i \in P}\left[c_{i}-\frac{\bar{w} \circ m_{i}^{-1}\left(m_{i}\right)}{w_{i}^{*}\left(m_{i}\right)} y_{i}+\bar{m} \circ m_{i}^{-1}\left(m_{i}\right)\right] \\
& \geq \min _{i \in N}\left[c_{i}-\frac{\bar{w} \circ m_{i}^{-1}\left(m_{i}\right)}{w_{i}^{*}\left(m_{i}\right)} y_{i}+\bar{m} \circ m_{i}^{-1}\left(m_{i}\right)\right]
\end{aligned}
$$

is an upper bound for $\min _{i} I T\left(z_{i}, R_{i}\right)$. We focus on the specification of this upper bound.

Under Preference Diversity, the intersection of the closed lower contour sets of all $i \in N$, on the subset of $(c, y, m)$ such that $y \leq \underline{w}^{*}(m)$, coincides with the intersection of the closed lower contour sets of all $i \in P$. Therefore, for all chosen bundles $\left(c_{i}, y_{i}, m_{i}\right)$ such that $y_{i} \leq \underline{w}^{*}\left(m_{i}\right)$, there is $j \in P$ such that $\left(c_{i}, y_{i}, m_{i}\right) I_{j}^{*}\left(c_{j}, y_{j}, m_{j}\right)$. For such $j$, one has

$$
I T\left(z_{j}, R_{j}\right) \leq c_{i}-\frac{\bar{w} \circ \underline{m}^{-1}\left(m_{i}\right)}{\underline{w}^{*}\left(m_{i}\right)} y_{i}+\bar{m} \circ \underline{m}^{-1}\left(m_{i}\right) .
$$

Therefore

$$
\min _{j \in P} \operatorname{IT}\left(z_{j}, R_{j}\right) \leq c_{i}-\frac{\bar{w} \circ \underline{m}^{-1}\left(m_{i}\right)}{\underline{w}^{*}\left(m_{i}\right)} y_{i}+\bar{m} \circ \underline{m}^{-1}\left(m_{i}\right) .
$$

The conclusion follows. 
Under Weak Preference Diversity, the same reasoning as in the previous paragraph holds on the subset of chosen $\left(c_{i}, y_{i}, m_{i}\right)$ such that $y_{i} \leq \underline{w}^{*}\left(m_{i}\right)$ and $\underline{b}_{\underline{\underline{w}}^{*}\left(m_{i}\right)}^{*} T\left(m_{i}\right)=\underline{\underline{b}}_{\underline{\underline{w}}^{*+}\left(m_{i}\right)}^{*}\left(m_{i}\right)$.

This result is important because it reduces the amount of information needed for policy evaluation to data that are more easily available to the policy-maker than the full distribution of population characteristics. Knowing the worst and average functions $w$ and $m$, it suffices to look at bundles in a well-defined area and, regarding the second part of the result, it is not difficult to locate and exclude the dominated part of the worst-type budget.

Apart from Corollary 2, in our results there is no guarantee that the worst-off individuals actually belong to the worst type. But this is plausible and it would not be difficult to make assumptions to this effect (e.g., assuming that all types of preference orderings $R_{i}$ found in the population are represented in $P$ ). However, this would not provide any different bounds than those obtained here, it would only probably make them closer to $\min _{i} I T\left(z_{i}, R_{i}\right)$. Nonetheless, the introduction of the Worst Type assumption considerably sharpens the scope of Proposition 1 as reflected by Propositions 3 and 4 whose practical implications are quite simple to grasp: even if the well-being of the worst off agent cannot necessarily be measured and she is not necessarily a member of $P$, still she is located in the region of the budget set that is attainable by a poor agent. This part of the budget set should be the primary focus of any reform.

\section{Optimal tax: the linear case}

In this section and the next one, we study some properties of the optimal tax scheme under the particular criterion of social welfare we are using.

We first restrict our attention to linear taxes. Namely,

$$
T(y, m)=\tau y-\rho m-\theta,
$$

where $\theta \in \mathbb{R}$ is a universal lump-sum grant while $\tau \in \mathbb{R}$ and $\rho \in \mathbb{R}$ are the parameters for marginal income tax rate and human capital subsidy rate. This implies that, for each agent $i \in N$, the budget set modified by the tax function is

$$
c_{i} \leq \theta+(1-\tau) y_{i}-(1-\rho) m_{i},
$$

or, in the $(c, l, h)$ space,

$$
c_{i} \leq \theta+(1-\tau) w_{i}\left(h_{i}\right) l_{i}-(1-\rho) m_{i}\left(h_{i}\right) .
$$


Let the indirect utility be defined as:

$$
v_{i}(\theta, \tau, \rho)=\max \left\{I T\left(\left(c_{i}, l_{i}, h_{i}\right), R_{i}\right) \mid c_{i} \leq \theta+(1-\tau) w_{i}\left(h_{i}\right) l_{i}-(1-\rho) m_{i}\left(h_{i}\right)\right\}
$$

and the behavior functions be denoted $\left(c_{i}(\theta, \tau, \rho), l_{i}(\theta, \tau, \rho), h_{i}(\theta, \tau, \rho)\right)$. By the envelope theorem, at the bundle chosen by the agent one has

$$
\begin{aligned}
\frac{\partial v_{i}}{\partial \theta} & =\frac{\partial}{\partial c_{i}} I T\left(\left(c_{i}, l_{i}, h_{i}\right), R_{i}\right) \\
\frac{\partial v_{i}}{\partial \tau} & =-y_{i} \frac{\partial v_{i}}{\partial \theta} \\
\frac{\partial v_{i}}{\partial \rho} & =m_{i} \frac{\partial v_{i}}{\partial \theta}
\end{aligned}
$$

Besides, the Slutsky equations imply

$$
\begin{aligned}
\frac{\partial l_{i}}{\partial \tau} & =\frac{\partial l_{i}^{c}}{\partial \tau}-y_{i} \frac{\partial l_{i}}{\partial \theta} \\
\frac{\partial m_{i}}{\partial \tau} & =\frac{\partial m_{i}^{c}}{\partial \tau}-y_{i} \frac{\partial m_{i}}{\partial \theta} \\
\frac{\partial l_{i}}{\partial \rho} & =\frac{\partial l_{i}^{c}}{\partial \rho}+m_{i} \frac{\partial l_{i}}{\partial \theta} \\
\frac{\partial m_{i}}{\partial \rho} & =\frac{\partial m_{i}^{c}}{\partial \rho}+m_{i} \frac{\partial m_{i}}{\partial \theta}
\end{aligned}
$$

where the superscript $c$ denotes compensated demands. The general budget constraint requires

$$
n \theta+\rho \sum_{i} m_{i}\left(h_{i}\right) \leq \tau \sum_{i} w_{i}\left(h_{i}\right) l_{i}
$$

Focusing on the maximin variant of our criterion, which is more convenient as it is continuous, ${ }^{13}$ we have the Lagrangean

$$
\mathcal{L}=\min _{i} v_{i}(\theta, \tau, \rho)+\lambda\left(\tau \sum_{i} w_{i}\left(h_{i}(\theta, \tau, \rho)\right) l_{i}(\theta, \tau, \rho)-n \theta-\rho \sum_{i} m_{i}\left(h_{i}(\theta, \tau, \rho)\right)\right) .
$$

There are two differences with Jacobs and Bovenberg [24]. First, our criterion is a maximin. Second, the agents may care about $h_{i}$, not just $\left(c_{i}, l_{i}\right)$.

It is a convenient simplification to assume that there is a sufficient diversity among the worstoff agents, so that the optimal tax policy will actually be the optimal tax for one of them. We will therefore study the following simplified problem, for a fixed $i_{0} \in P$ :

$$
\mathcal{L}=v_{i_{0}}(\theta, \tau, \rho)+\lambda\left(\tau \sum_{i} w_{i}\left(h_{i}(\theta, \tau, \rho)\right) l_{i}(\theta, \tau, \rho)-n \theta-\rho \sum_{i} m_{i}\left(h_{i}(\theta, \tau, \rho)\right)\right) .
$$

\footnotetext{
${ }^{13}$ This is not a restriction, because the optimal tax for the leximin must in particular be optimal for the maximin. Therefore all conclusions derived from the maximin hold for the optimal leximin policy.
} 
Let us start with a more general program:

$$
\mathcal{L}=\sum_{i} \alpha_{i} v_{i}(\theta, \tau, \rho)+\lambda\left(\tau \sum_{i} w_{i}^{*}\left(m_{i}(\theta, \tau, \rho)\right) l_{i}(\theta, \tau, \rho)-n \theta-\rho \sum_{i} m_{i}(\theta, \tau, \rho)\right) .
$$

The first order conditions (FOC) for $\theta$ gives $\sum_{i} b_{i}=n$, where $b_{i}$ is the marginal social value of giving $\$ 1$ to $i_{0}$, taking account of the impact on the tax base:

$$
b_{i}=\frac{\alpha_{i}}{\lambda} \frac{\partial v_{i}}{\partial \theta}+\tau\left(w_{i}^{* \prime} \frac{\partial m_{i}}{\partial \theta} l_{i}+w_{i}^{*} \frac{\partial l_{i}}{\partial \theta}\right)-\rho \frac{\partial m_{i}}{\partial \theta} .
$$

The FOC for $\tau$ and $\rho$ are:

$$
\begin{aligned}
\sum_{i}\left[\alpha_{i} \frac{\partial v_{i}}{\partial \tau}+\lambda\left(y_{i}+\tau\left(w_{i}^{* \prime} \frac{\partial m_{i}}{\partial \tau} l_{i}+w_{i}^{*} \frac{\partial l_{i}}{\partial \tau}\right)-\rho \frac{\partial m_{i}}{\partial \tau}\right)\right] & =0 \\
\sum_{i}\left[\alpha_{i} \frac{\partial v_{i}}{\partial \rho}+\lambda\left(\tau\left(w_{i}^{* \prime} \frac{\partial m_{i}}{\partial \rho} l_{i}+w_{i}^{*} \frac{\partial l_{i}}{\partial \rho}\right)-m_{i}-\rho \frac{\partial m_{i}}{\partial \rho}\right)\right] & =0 .
\end{aligned}
$$

One has:

$$
\begin{aligned}
& \frac{\alpha_{i}}{\lambda} \frac{\partial v_{i}}{\partial \tau}+\left(y_{i}+\tau\left(w_{i}^{* \prime} \frac{\partial m_{i}}{\partial \tau} l_{i}+w_{i}^{*} \frac{\partial l_{i}}{\partial \tau}\right)-\rho \frac{\partial m_{i}}{\partial \tau}\right) \\
= & -y_{i} \frac{\alpha_{i}}{\lambda} \frac{\partial v_{i}}{\partial \theta}+y_{i}+\left(\frac{\partial m_{i}^{c}}{\partial \tau}-y_{i} \frac{\partial m_{i}}{\partial \theta}\right)\left(\tau w_{i}^{* \prime} l_{i}-\rho\right)+\tau w_{i}^{*}\left(\frac{\partial l_{i}^{c}}{\partial \tau}-y_{i} \frac{\partial l_{i}}{\partial \theta}\right) \\
= & \left(1-b_{i}\right) y_{i}+\left(\frac{\partial m_{i}^{c}}{\partial \tau}\right)\left(\tau w_{i}^{* \prime} l_{i}-\rho\right)+\tau w_{i}^{*}\left(\frac{\partial l_{i}^{c}}{\partial \tau}\right) \\
= & \left(1-b_{i}\right) y_{i}+\frac{\partial \ln m_{i}^{c}}{\partial \ln \tau} \frac{d \ln w_{i}^{*}}{d \ln m_{i}} y_{i}-\frac{\rho}{\tau} \frac{m_{i}}{y_{i}} \frac{\partial \ln m_{i}^{c}}{\partial \ln \tau} y_{i}+y_{i} \frac{\partial \ln l_{i}^{c}}{\partial \ln \tau}
\end{aligned}
$$

Therefore the FOC for $\tau$ can be written, letting a bar indicate an average weighted by $y_{i}$ :

$$
1-\bar{b}+\overline{\frac{\partial \ln m^{c}}{\partial \ln \tau} \frac{d \ln w^{*}}{d \ln m}}-\frac{\rho}{\tau} \overline{\frac{m}{y} \frac{\partial \ln m^{c}}{\partial \ln \tau}}+\overline{\frac{\partial \ln l^{c}}{\partial \ln \tau}}=0 .
$$

In similar fashion, the FOC for $\rho$ can be rewritten

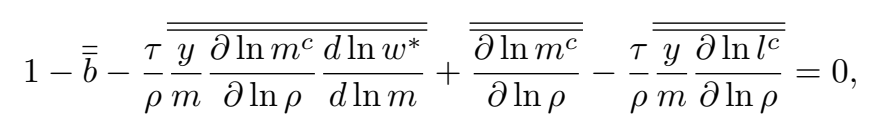

where a double bar marks an average weighted by $m_{i}$.

Both equations deliver a formula for $\tau / \rho$ :

$$
\begin{aligned}
& \frac{\tau}{\rho}=\frac{\frac{m}{y} \frac{\partial \ln m^{c}}{\partial \ln \tau}}{1-\bar{b}+\frac{\overline{\partial \ln m^{c}}}{\partial \ln \tau} \frac{d \ln w^{*}}{d \ln m}+\overline{\frac{\partial \ln l^{c}}{\partial \ln \tau}}}, \\
& \frac{\tau}{\rho}=\frac{1-\overline{\bar{b}}+\frac{\overline{\overline{\partial \ln m^{c}}}}{\partial \ln \rho}}{\overline{\frac{y}{m} \frac{\partial \ln m^{c}}{\partial \ln \rho} \frac{d \ln w^{*}}{d \ln m}}+\overline{\overline{\frac{y}{m} \frac{\ln l^{c}}{\partial \ln \rho}}}} .
\end{aligned}
$$

If the worst-off is an agent with low $y_{i_{0}}$ and high $m_{i_{0}}$, compared to equal weights $\alpha_{i}$ this tends to lower $\bar{b}$ and raise $\overline{\bar{b}}$, therefore implying a lower $\tau$ and a greater $\rho$. 
Of course these equations contain many endogenous variables which vary as well. Jacobs and Bovenberg [24] show that when individuals do not care about $h_{i}$ directly, and when $w_{i}^{*}$ has the same constant elasticity for all $i$, then $\tau=\rho$, independently of the degree of inequality aversion in the social objective. ${ }^{14}$ Their result remains true here. ${ }^{15}$

Following the reasoning of Piketty and Saez [33] and using the same social welfare function (9) one can obtain separate formulas for $\tau$ and $\rho$. Let $\theta(\tau, \rho)$ denote the maximum $\theta$ compatible with the budget constraint for a given pair $(\tau, \rho)$. Plugging $\theta(\tau, \rho)$ into equation $(8)$ one obtains a budget identity that is function of two parameters only $(\tau, \rho)$. That is,

$$
n \theta(\tau, \rho)+\rho M(\theta(\tau, \rho), \tau, \rho)=\tau Y(\theta(\tau, \rho), \tau, \rho),
$$

where

$$
M(\theta, \tau, \rho)=\sum_{i} m_{i}\left(h_{i}\left(\theta, \tau, \rho, w_{i}(.), m_{i}(.)\right)\right)
$$

and

$$
Y(\theta, \tau, \rho)=\sum_{i} w_{i}\left(h_{i}\left(\theta, \tau, \rho, w_{i}(.), m_{i}(.)\right)\right) l_{i}\left(\theta, \tau, \rho, w_{i}(.), m_{i}(.)\right) .
$$

The budget set of any agent $i \in N$ can then simply be rewritten as

$$
c_{i}=(1-\tau) w_{i}^{*}\left(m_{i}\right) l_{i}-(1-\rho) m_{i}+\theta(\tau, \rho),
$$

and the program in (9) as:

$$
\left.\max _{\tau, \rho}=\sum_{i} \alpha_{i} u_{i}\left((1-\tau) w_{i}^{*}\left(m_{i}(\tau, \rho)\right) l_{i}(\tau, \rho)\right)-(1-\rho) m_{i}(\tau, \rho)+\theta(\tau, \rho), l_{i}(\tau, \rho), m_{i}^{-1}\left(m_{i}(\tau, \rho)\right)\right)
$$

where $u_{i}$ is the direct utility function of agent $i \in N$. From the FOC of this program, using the envelope theorem, one derives the following formulas (notation: $Y_{\theta}=\partial Y / \partial \theta$, and so on):

$$
\begin{gathered}
\tau=\frac{\left(Y-n g_{y}\right)\left(M_{\theta} \theta_{\rho}+M_{\rho}\right)+\left(M-n g_{m}\right)\left(M_{\theta} \theta_{\tau}+M_{\tau}\right)}{\left(M_{\theta} \theta_{\tau}+M_{\tau}\right)\left(Y_{\theta} \theta_{\rho}+Y_{\rho}\right)-\left(M_{\theta} \theta_{\rho}+M_{\rho}\right)\left(Y_{\theta} \theta_{\tau}+Y_{\tau}\right)}, \\
\rho=\frac{\left(Y-n g_{y}\right)\left(Y_{\theta} \theta_{\rho}+Y_{\rho}\right)+\left(M-g_{m}\right)\left(Y_{\theta} \theta_{\tau}+Y_{\tau}\right)}{\left(M_{\theta} \theta_{\tau}+M_{\tau}\right)\left(Y_{\theta} \theta_{\rho}+Y_{\rho}\right)-\left(M_{\theta} \theta_{\rho}+M_{\rho}\right)\left(Y_{\theta} \theta_{\tau}+Y_{\tau}\right)}, \\
\frac{\tau}{\rho}=\frac{\left(Y-n g_{y}\right)\left(M_{\theta} \theta_{\rho}+M_{\rho}\right)+\left(M-n g_{m}\right)\left(M_{\theta} \theta_{\tau}+M_{\tau}\right)}{\left(Y-n g_{y}\right)\left(Y_{\theta} \theta_{\rho}+Y_{\rho}\right)+\left(M-g_{m}\right)\left(Y_{\theta} \theta_{\tau}+Y_{\tau}\right)},
\end{gathered}
$$

\footnotetext{
${ }^{14}$ Under these assumptions, $y_{i}$ and $m_{i}$ are proportional, so that the single-barred and double-barred averages coincide.

${ }^{15}$ Actually, their proof is valid for agents with heterogeneous preferences, even if their model assumes identical preferences.
} 
where

$$
g_{y}=\sum_{i} \frac{\alpha_{i} \frac{\partial u_{i}(.)}{\partial c_{i}}}{\sum_{i} \alpha_{i} \frac{\partial u_{i}(.)}{\partial c_{i}}} y_{i}
$$

is the sum of pre-tax incomes $y_{i}$ weighted by the normalized social marginal welfare weights, and

$$
g_{m}=\sum_{i} \frac{\alpha_{i} \frac{\partial u_{i}(\cdot)}{\partial c_{i}}}{\sum_{i} \alpha_{i} \frac{\partial u_{i}(.)}{\partial c_{i}}} m_{i}
$$

is the sum of human capital expenditures $m_{i}$ weighted by normalized social marginal welfare weights. If the social planner has no interest whatsoever for redistribution then $g_{y}=\frac{Y}{n}$ and $g_{m}=\frac{M}{n}$ so that $\rho=0$ and $\tau=0 .{ }^{16}$

More relevantly, if the focus of the social planner is exclusively on the worst off $i_{0}$, then $g_{y}=y_{0}$ and $g_{m}=m_{0}$. Moreover, the optimal tax for $i_{0} \in P$ satisfies

$$
\frac{\partial v_{i_{0}}}{\partial \tau}+\frac{\partial v_{i_{0}}}{\partial \theta} \theta_{\tau}=\left(\theta_{\tau}-y_{i_{0}}\right) \frac{\partial v_{i_{0}}}{\partial \theta}=0
$$

and

$$
\frac{\partial v_{i_{0}}}{\partial \rho}+\frac{\partial v_{i_{0}}}{\partial \theta} \theta_{\rho}=\left(\theta_{\rho}+m_{i_{0}}\right) \frac{\partial v_{i_{0}}}{\partial \theta}=0
$$

implying $\theta_{\tau}=y_{i}$ and $\theta_{\rho}=-m_{i}$.

Plugging the optimal tax conditions for $i_{0}$ into equation (13), one gets:

$$
\frac{\tau}{\rho}=\frac{\left(M_{\theta} y_{i_{0}}+M_{\tau}\right)\left(M / n-m_{i_{0}}\right)+\left(-M_{\theta} m_{i_{0}}+M_{\rho}\right)\left(Y / n-y_{i_{0}}\right)}{\left(Y_{\theta} y_{i_{0}}+Y_{\tau}\right)\left(M / n-m_{i_{0}}\right)+\left(-Y_{\theta} m_{i_{0}}+Y_{\rho}\right)\left(Y / n-y_{i_{0}}\right)}
$$

and, in the case of quasi-linear preferences (for which $Y_{\theta}=M_{\theta}=0$ ):

$$
\frac{\tau}{\rho}=\frac{M_{\tau}\left(M / n-m_{i_{0}}\right)+M_{\rho}\left(Y / n-y_{i_{0}}\right)}{Y_{\tau}\left(M / n-m_{i_{0}}\right)+Y_{\rho}\left(Y / n-y_{i_{0}}\right)} .
$$

${ }^{16}$ Still following Piketty and Saez [33] one can also express the previous formulas in terms of elasticities. Let in particular $\varepsilon_{Y \tau}=\frac{\partial Y}{\partial(1-\tau)} \frac{(1-\tau)}{Y}$ denote the elasticity of total earnings with respect to the net-of-tax rate, $\varepsilon_{M \tau}=$ $\frac{\partial M}{\partial(1-\tau)} \frac{(1-\tau)}{M}$ the elasticity of total human capital expenditure with respect to the net-of-tax rate, $\varepsilon_{Y \rho}=\frac{\partial Y}{\partial(1-\rho)} \frac{(1-\rho)}{Y}$ the elasticity of total earnings with respect to the net-of-subsidy rate and $\varepsilon_{M \rho}=\frac{\partial M}{\partial(1-\rho)} \frac{(1-\rho)}{M}$ the elasticity of total human capital expenditure with respect to the net-of-subsidy rate. One can then recast the formulas for $\tau$ and $\rho$ in terms of such elasticities:

$$
\begin{gathered}
\tau=\frac{\left(M-n g_{m}\right)\left(Y-n g_{y}\right)+M\left(\left(M-n g_{m}\right) \varepsilon_{M \tau}+\left(Y-n g_{y}\right) \varepsilon_{M \rho}\right)}{\left(M-n g_{m}\right)\left(Y-n g_{y}\right)+\left(Y-n g_{y}\right) \varepsilon_{M \rho} M+\left(M-n g_{m}\right) \varepsilon_{Y \rho} Y+Y M\left(\varepsilon_{M \rho} \varepsilon_{Y \rho}-\varepsilon_{M \tau} \varepsilon_{Y \tau}\right)} \\
\rho=\frac{\left(M-n g_{m}\right)\left(Y-n g_{y}\right)+Y\left(\left(M-n g_{m}\right) \varepsilon_{Y \tau}+\left(Y-n g_{y}\right) \varepsilon_{Y \rho}\right)}{\left(M-n g_{m}\right)\left(Y-n g_{y}\right)+\left(Y-n g_{y}\right) \varepsilon_{M \rho} M+\left(M-n g_{m}\right) \varepsilon_{Y \rho} Y+Y M\left(\varepsilon_{M \rho} \varepsilon_{Y \rho}-\varepsilon_{M \tau} \varepsilon_{Y \tau}\right)} .
\end{gathered}
$$


We will focus on the standard situation in which

$$
Y_{\rho} \geq 0 ; M_{\rho} \geq 0
$$

and, moreover,

$$
Y_{\tau} \leq 0 ; M_{\tau} \leq 0
$$

The first two inequalities can be explained by the fact that if $\rho$ increases, the total human capital expenditure increases too. This makes agents more productive so that they (eventually) work more and earn more. The latter inequalities can be explained by the fact that if $\tau$ increases, agents work less and earn less, this also reduces the payoff of human capital and hence the human capital expenditure. Moreover, if income effects are not too strong, the previous inequalities also yield

$$
\begin{aligned}
M_{\theta} y_{i_{0}}+M_{\tau} & \leq 0 \leq-M_{\theta} m_{i_{0}}+M_{\rho}, \\
Y_{\theta} y_{i_{0}}+Y_{\tau} & \leq 0 \leq-Y_{\theta} m_{i_{0}}+Y_{\rho} .
\end{aligned}
$$

Finally, if $m_{i}>M / n$ and $y_{i}<Y / n$, then $\tau$ and $\rho$ have the same sign, which will be positive if ${ }^{17}$

$$
\left(M_{\theta} y_{i_{0}}+M_{\tau}\right)\left(-Y_{\theta} m_{i_{0}}+Y_{\rho}\right)>\left(-M_{\theta} m_{i_{0}}+M_{\rho}\right)\left(Y_{\theta} y_{i_{0}}+Y_{\tau}\right)
$$

a plausible condition. In particular, in the quasi-linear case, this condition boils down to $M_{\tau} Y_{\rho}>$ $M_{\rho} Y_{\tau}$, which is very likely to occur because $Y$ should be more sensitive to $\tau$ than to $\rho$, whereas the opposite holds for $M$.

So, under the assumptions we have listed so far, what does ultimately determine the mix of income redistribution and human capital subsidies? If $M_{\rho}$ is much greater than $\left|M_{\tau}\right|$ and $\left|Y_{\tau}\right|$ is much greater than $Y_{\rho}$, and if $M_{\theta}$ and $\left|Y_{\theta}\right|$ are sufficiently small, the prominent terms in (14) and (15) form the ratio

$$
\frac{M_{\rho}\left(Y / n-y_{i_{0}}\right)}{Y_{\tau}\left(M / n-m_{i_{0}}\right)}
$$

and provide a simple message. More redistribution than subsidizing will take place if human capital expenditures react strongly to subsidies whereas earnings react less to tax (this reflects the incentive concern), and if the gap between the relevant worst-off agent and the average situation is greater in earnings and smaller in human capital expenditures (this reflects the inequality concern).

This simple message is refined by adding the other components of the ratios in (14) and (15). In particular, more income redistribution in the mix will be pushed by a greater sensitivity of $M$

\footnotetext{
${ }^{17}$ This determines the sign of the denominator in (11) and (12).
} 
to income tax and a lower sensitivity of $Y$ to human capital subsidies. These results also suggest that it may be optimal to tax human capital expenditures if the worst-off agents spend less than average in human capital or, alternatively, earn more than average. The former case does not appear unrealistic in the context of education.

The following simulations illustrate this possibility. We consider a simple economy consisting of eight equally sized subgroups, varying in three dimensions: preferences, earning ability (function), human capital disposition. Preferences are expressed by the following utility functions: either $u^{f}(c, l, h)=c+\sqrt{(1-l) h}$ or $u^{s}(c, l, h)=c+1.5 \sqrt{(1-l) h}$; earning abilities are either $w^{f}=\sqrt{h}$ or $w^{s}=2 \sqrt{h}$; health dispositions is either $m^{s}(h)=h^{2}$ or $m^{f}(h)=2 h^{2}$. The average earning ability is therefore $\bar{w}(h)=1.5 \sqrt{h}$ whilst the average human capital disposition is $\bar{m}(h)=1.5 h^{2}$. In this economy the optimal policy is approximately $\tau=.35$ and $\rho=-.13$, with $\theta=.21$. The worst-off type's (first type of preferences, lowest earning ability, worst human capital disposition) human capital expenditure is .09 units below the average. The particular feature of this example is that the worst-off agents have the type of preferences with lowest concern for leisure and for human capital.

It must be emphasized, however, that even in this kind of economy, lower-than-average human capital expenditures on behalf of the worst-off is not sufficient to induce an optimal tax (i.e., a negative subsidy) on such expenditures, because the other terms in (15) can dominate. If, compared to the previous example we consider preferences represented by the following utility functions $u^{f}(c, l, h)=c+\sqrt{(1-l) h}$ and $u^{s}(c, l, h)=c+2 \sqrt{(1-l) h}$ and the earning abilities $w^{f}(h)=2 \sqrt{h}$ and $w^{s}(h)=4 \sqrt{h}$ (while keeping the same human capital dispositions), then the optimal policy is approximately $\tau=.39$ and $\rho=.03$, with $\theta=.69$. The worst-off type's human capital expenditure is .22 units below the average but $\rho$ is positive even if strikingly low. This is because the term $Y_{\tau}\left(M / n-m_{i}\right)$ (in (15)) is substantially negative, even though it ends up being counterbalanced by the positive term $Y_{\rho}\left(Y / n-y_{i}\right)$ because of the great gap $Y / n-y_{i}$.

\section{Optimal tax: the non-linear case}

Describing the optimal non-linear tax policy is extremely hard when the individuals differ in many dimensions and their behavior unfolds in a three-dimensional space. We will focus on a specific aspect of the optimal tax which is nevertheless quite central in understanding the shape 
of the optimal policy. Our goal is to determine what sort of agent (type, behavior) will receive the greatest subsidy at the second-best optimum. Let $z^{*}$ be an optimal incentive-compatible allocation implemented by the optimal tax function $T^{*}(y, m)$. The following proposition identifies a way to cut subsidies above a certain level without harming the role of $t_{0}^{*}$ (as defined in section 5.2) as a lower bound for well-being as measured by $I T$.

Proposition 5 Assume Worst Type holds. Let $T^{*}(y, m)$ implement $z^{*}$, let $t_{0}^{*}$ be the greatest value of $t_{0}$ such that $B\left(t_{0}, \bar{w}(),. \bar{m}().\right) \subset B_{\cap}^{+}\left(T^{*}\right)$, and let $r^{*}$ be equal to the maximum of $\bar{w}(h)-\underline{w}(h)-$ $\bar{m}(h)+\underline{m}(h)$ for $h \in[0,1]$ such that $t_{0}^{*}+\bar{w}(h)-\bar{m}(h) \geq 0$. Then the tax function

$$
T^{* *}(y, m)=\max \left\{T^{*}(y, m),-t_{0}^{*}-r^{*}\right\}
$$

is feasible and satisfies

$$
t_{0}^{*} \leq \min _{i} I T_{i}\left(z_{i}^{* *}, R_{i}\right)
$$

for any allocation $z^{* *}$ that $T^{* *}$ induces.

Proof. The new tax, $T^{* *}(y, m)$, reduces the budget set by cutting all subsidies above $t_{0}^{*}+r^{*}$. Consider any $i \in N$ and the couple $\left(y_{i}^{*}, m_{i}^{*}\right)$ chosen by agent $i$ under $T^{*}$. If $T^{*}\left(y_{i}^{*}, m_{i}^{*}\right) \geq$ $-\left(t_{0}^{*}+r^{*}\right)$, then $z_{i}^{*}$ is still an attainable option under $T^{* *}$, therefore it is still the best choice for $i$. If $T^{*}\left(y_{i}^{*}, m_{i}^{*}\right)<-\left(t_{0}^{*}+r^{*}\right)$, then $z_{i}^{*}$ is no longer accessible to $i$, and at the new best bundle $z_{i}^{* *}$ chosen under $T^{* *}, T^{* *}\left(y_{i}^{* *}, m_{i}^{* *}\right) \geq-\left(t_{0}^{*}+r^{*}\right)$, therefore $T^{* *}\left(y_{i}^{* *}, m_{i}^{* *}\right)>T^{*}\left(y_{i}^{*}, m_{i}^{*}\right)$. Hence, if there are agents $i \in N$ for whom $z_{i}^{*}$ is no longer accessible under $T^{* *}$, they will chose a new bundle such that the new allocation $z^{* *}$ generates a surplus. In any case, $z^{* *}$ is by construction feasible.

Suppose that $B\left(t_{0}^{*}, \bar{w}(),. \bar{m}().\right) \subset B_{\cap}^{+}\left(T^{* *}\right)$. Then, by Prop. $1, t_{0}^{*} \leq \min _{i} I T_{i}\left(z_{i}^{* *}, R_{i}\right)$. It is therefore sufficient to prove that $B\left(t_{0}^{*}, \bar{w}(),. \bar{m}().\right) \subset B_{\cap}^{+}\left(T^{* *}\right)$.

By Worst Type, $B_{\cap}^{+}\left(T^{* *}\right)=\underline{B}^{+}\left(T^{* *}\right)$. By construction,

$$
\underline{B}^{+}\left(T^{* *}\right)=\underline{B}^{+}\left(T^{*}\right) \cap\left\{(c, l, h) \in Z \mid c \leq \underline{w}(h) l-\underline{m}(h)+t_{0}^{*}+r^{*}\right\} .
$$

As $B\left(t_{0}^{*}, \bar{w}(),. \bar{m}().\right) \subset \underline{B}^{+}\left(T^{*}\right)$, it is sufficient to prove that

$$
B\left(t_{0}^{*}, \bar{w}(.), \bar{m}(.)\right) \subset\left\{(c, l, h) \in Z \mid c \leq \underline{w}(h) l-\underline{m}(h)+t_{0}^{*}+r^{*}\right\} .
$$

Suppose this does not hold. Then there is $(c, l, h) \in B\left(t_{0}^{*}, \bar{w}(),. \bar{m}().\right)$ such that $c>\underline{w}(h) l-$ $\underline{m}(h)+t_{0}^{*}+r^{*}$, implying

$$
t_{0}^{*}+\bar{w}(h) l-\bar{m}(h) \geq c>\underline{w}(h) l-\underline{m}(h)+t_{0}^{*}+r^{*},
$$


therefore

$$
r^{*}<\bar{w}(h) l-\underline{w}(h) l-\bar{m}(h)+\underline{m}(h) .
$$

The right-hand side is increasing in $l$, so one must have

$$
r^{*}<\bar{w}(h)-\underline{w}(h)-\bar{m}(h)+\underline{m}(h) .
$$

In addition, as $(c, l, h) \in B\left(t_{0}^{*}, \bar{w}(),. \bar{m}().\right)$,

$$
0 \leq t_{0}^{*}+\bar{w}(h) l-\bar{m}(h) \leq t_{0}^{*}+\bar{w}(h)-\bar{m}(h)
$$

One therefore obtains a contradiction with the definition of $r^{*}$.

The previous proposition proves that constructing $T^{* *}$ from $T^{*}$ does not necessarily entails a large welfare loss in the sense that $t_{0}^{*}$ remains a lower bound for the worst off at the allocation generated by both tax functions. The following corollary identifies the conditions under which the two tax functions are welfare equivalent, namely, the conditions under which $T^{* *}$ is optimal as well.

Corollary 6 Under the conditions of Proposition 5, if $t_{0}^{*}=\min _{i} I T_{i}\left(z_{i}^{*}, R_{i}\right)$, then $t_{0}^{*}=$ $\min _{i} I T_{i}\left(z_{i}^{* *}, R_{i}\right)$ and $z^{*}$ is implemented by $T^{* *}$.

Proof. This derives from the fact that by construction, $I T_{i}\left(z_{i}^{* *}, R_{i}\right) \leq I T_{i}\left(z_{i}^{*}, R_{i}\right)$ for all $i$, and by Proposition $5, t_{0}^{*} \leq \min _{i} I T_{i}\left(z_{i}^{* *}, R_{i}\right)$. In the proof of Proposition 5 it was shown that if $T^{* *}$ cannot implement $z^{*}$ (because $z_{i}^{*}$ is no longer affordable for some $i$ ), then $z^{* *}$ generates a surplus. But if this is the case, it is possible to distribute the surplus so as to raise $I T_{i}$ for every $i .{ }^{18}$ This would contradict the fact that $z^{*}$ is optimal and therefore maximizes $\min _{i} I T_{i}\left(z_{i}^{*}, R_{i}\right)$.

These results suggest that it is interesting to study $T^{* *}$. Note that even if $t_{0}^{*}<$ $\min _{i} I T_{i}\left(z_{i}^{*}, R_{i}\right)$, one has

$$
t_{0}^{*} \leq \min _{i} I T_{i}\left(z_{i}^{* *}, R_{i}\right) \leq \min _{i} I T_{i}\left(z_{i}^{*}, R_{i}\right)
$$

so that if $t_{0}^{*}$ is close to $\min _{i} I T_{i}\left(z_{i}^{*}, R_{i}\right)$, the allocation $z^{* *}$ is close to being optimal. Therefore, when looking at the optimal tax scheme, there is no loss, or a limited loss, of social welfare if one

\footnotetext{
${ }^{18}$ Doing such a distribution while preserving incentive compatibility is not trivial. See [16] for a rigorous proof in the Mirrlees model. The argument can be extended to the present model, as the dimension of the other goods than $c$ does not matter.
} 
restricts her attention to taxes that share the salient features of $T^{* *}$. In what follows we describe some of these features.

What is interesting about $T^{* *}$ is that it generates a budget $c=y-m-T^{* *}(y, m)$ which lies between the hyperplane $c=y-m+t_{0}^{*}+r^{*}$ and the manifold defined by

$$
y \leq \underline{w}^{*}(m) \text { and } c=y \frac{\bar{w} \circ \underline{m}^{-1}(m)}{\underline{w}^{*}(m)}-\bar{m} \circ \underline{m}^{-1}(m)+t_{0}^{*} .
$$

The former fact is a direct consequence of $T^{* *}(y, m) \geq-\left(t_{0}^{*}+r^{*}\right)$; the latter is nothing but the translation, in the $(c, y, m)$ space, of the fact that $B\left(t_{0}^{*}, \bar{w}(),. \bar{m}().\right) \subset \underline{B}^{+}\left(T^{* *}\right)$. Indeed, in the $(c, l, h)$ space the equation defining $B\left(t_{0}^{*}, \bar{w}(),. \bar{m}().\right)$ is $c=\bar{w}(h) l-\bar{m}(l)+t_{0}^{*}$. Substituting $l=y / \underline{w}(h) \leq 1$ and $h=\underline{m}^{-1}(m)$ yields the manifold described by (17).

The intersection between the hyperplane and the manifold determines the sort of individual who receives the greatest subsidy. The intersection is determined by the equation

$$
y-m+t_{0}^{*}+r^{*}=y \frac{\bar{w} \circ \underline{m}^{-1}(m)}{\underline{w}^{*}(m)}-\bar{m} \circ \underline{m}^{-1}(m)+t_{0}^{*},
$$

but, more simply, corresponds to the point which defines $r^{*}$, i.e., the maximum of $\bar{w}(h)-\underline{w}(h)-$ $\bar{m}(h)+\underline{m}(h)$ for $h \in[0,1]$ such that $t_{0}^{*}+\bar{w}(h)-\bar{m}(h) \geq 0$. This means in particular that $l=1$ at this point, i.e., the greatest subsidy goes to full-time work. It remains to determine the value of $h$ or $m$ at the maximum. The maximum can be obtained either at a point $h^{*}$ satisfying

$$
\bar{w}^{\prime}\left(h^{*}\right)-\underline{w}^{\prime}\left(h^{*}\right)-\bar{m}^{\prime}\left(h^{*}\right)+\underline{m}^{\prime}\left(h^{*}\right)=0,
$$

or at a point such that $t_{0}^{*}+\bar{w}(h)-\bar{m}(h)=0$. The latter case will be obtained in particular if $\bar{w}^{\prime}(h)>\underline{w}^{\prime}(h)$ and $\underline{m}^{\prime}(h) \geq \bar{m}^{\prime}(h)$ for all $h$.

In conclusion, the greatest subsidy is obtained by some agent who belongs to $P$ and works full time and either spends $\underline{m}\left(h^{*}\right)$ as defined above or has a null consumption because of great human capital expenditures. The other agents who belong to $P$ and also work full time, but have lower human capital expenditures, face a non-negative marginal rate of subsidy for human capital expenditures (on average over this part of their budget), whereas those who have greater expenditures face a non-positive rate of subsidy on average. This is due to the fact that their budget set under $T^{* *}$ has to lie below the hyperplane at which the rate of subsidy is null.

Similarly, the agents (from $P$ or not from $P$ ) who spend $\underline{m}\left(h^{*}\right)$ and earn less than $\underline{w}\left(h^{*}\right)$ face on average over this range of earnings a non-positive marginal tax rate. But note that when $t_{0}^{*}+\bar{w}\left(h^{*}\right)-\bar{m}\left(h^{*}\right)=0$ there are no such agents because consumption is below zero in this area. 
Let us briefly compare our results to those of Fleurbaey and Maniquet [17] for the Mirrlees model (with exogenous human capital). They obtained the general conclusion that at an optimal allocation for a similar social ordering (egalitarian-equivalent with reference wage equal to the average) it was possible to have a tax function with a marginal rate that is non-positive on average over income below the lowest wage, with a greatest subsidy granted to the least skilled individuals working full time. They relied on a preference diversity assumption.

Here we have avoided this assumption because it is restrictive (it is technically interesting to understand what can be said in absence of this assumption) in our setting, and nevertheless obtained a similar focus on the hardworking poor. But there are two more important differences. First, the focus is no longer on the least skilled agents but on the agents with the least favorable dispositions. Agents with the lowest skills but better dispositions than the worst type are not considered among the worst-off here. Second, for the same reason, the advantage given to hardworking agents is now restricted to those who have significant human capital expenditures. The low skilled agents with a better human capital disposition (and a lower expenditure) may face substantial tax rates on earnings if this helps funding the human capital subsidy.

Of course, this more complex configuration comes in part from the fact that we studied the most general tax function $T(y, m)$ with any possible interdependence between the tax on $y$ and the subsidy on $m$. The study of the special but interesting case of separate non-linear instruments $T(y), S(m)$ is not undertaken in this paper.

\section{Observable human capital}

We will turn now our attention to a different informational context. Let us assume that $h$ is observed, together with $c, y$ and $m$. This amounts to saying that, for instance, when it comes to education, the policy maker can observe the diplomas an agent has. Alternatively one could think of health. In this case our assumption implies that the social planner can rely on the physicians evaluation in order to assess agents' health status. In such an informational framework the incentive-compatibility constraint becomes: for all $i, j$,

$$
\left(c_{i}, y_{i}, m_{i}\right) R_{i}^{*}\left(c_{j}, y_{j}, m_{j}\right) \text { or } y_{j}>w_{i}^{*}\left(m_{i}\right) \text { or } m_{i}\left(h_{j}\right) \neq m_{j}\left(h_{j}\right)
$$


As in the previous setting, agent $i$ still has to receive an allocation that she prefers to the allocation received by agent $j$ unless it is not possible for her to mimic agent $j$. This occurs either if $y_{j}>w_{i}^{*}\left(m_{i}\right)$ (exactly as in the previous framework) or if $m_{i}\left(h_{j}\right) \neq m_{j}\left(h_{j}\right)$. That is, agent $i$ can pretend to have agent $j$ 's human capital disposition only if her human capital disposition function crosses $j$ 's function at $h=h_{j} .{ }^{19}$ To simplify the analysis and to better analyze the consequences of using an egalitarian social objective we introduce the following assumption:

Assumption 4 (Nested Types) The $m_{i}$ functions do not cross, i.e., there is no $i, j$ such that for some $h, h^{\prime}, m_{i}(h)>m_{j}(h)$ and $m_{i}\left(h^{\prime}\right)<m_{j}\left(h^{\prime}\right)$.

This assumption allows us to partition the population into different subgroups of agents having the same human capital disposition. Let $K$ denote the set of subgroups resulting from such a partition. The fact that the human capital level is observable entails that one can conceive a different tax policy $T_{k}(y, m)$ for each $k \in K$.

We also introduce a further assumption which is meant to rule out a strict relation between having a good earning ability and a good human capital disposition. Whatever the human capital disposition, there is always some agent with the worst earning ability belonging to such group. Correlation is however permitted.

Assumption 5 (Uniformity): For every $k=1, \ldots, K$, there is $i$ in subgroup $k$ such that $w_{i}(h)=\underline{w}(h)$.

This assumption just rules out the possibility for the policy maker to conceive a tax scheme that is particularly harsh to some specific subgroup $k$ just because she happens to know that no unskilled agents belong to that subgroup. Let $P_{k}$ denote the subset of $i$ from subgroup $k$ such that $w_{i}=\underline{w}$.

\footnotetext{
${ }^{19}$ An alternative specification would allow agents to "inflate" their expenditures and pretend they have a worse $m$ function than they really have. In this case the incentive-compatibility constraint would become:for all $i, j$,

$$
\left(c_{i}, y_{i}, m_{i}\right) R_{i}^{*}\left(c_{j}, y_{j}, m_{j}\right) \text { or } y_{j}>w_{i}^{*}\left(m_{i}\right) \text { or } m_{i}\left(h_{j}\right)>m_{j}\left(h_{j}\right)
$$

This alternative setting would give some protection to agents with a better disposition. However the practical implications would not be very different since we rely on an egalitarian social welfare function anyway. Hence we stick to the setting presented in the main text which is simpler.
} 
Let also $\underline{B}_{k}^{+}(T)$ denote the budget set of some agent belonging to $P_{k}$, for $k \in K$.

Consider the budget $B\left(t_{0}^{*}, \bar{w}(),. \bar{m}().\right)$ of a hypothetical agent with average circumstances, under laissez-faire except for a lump-sum transfer $t_{k} \in \mathbb{R}$ :

$$
c \leq \bar{w}(h) l-\bar{m}(h)+t_{k}
$$

For any $k \in K$ and for $t_{k}$ small enough (possibly negative), this budget $B\left(t_{k}^{*}, \bar{w}(),. \bar{m}().\right)$ is contained in $\underline{B}_{k}^{+}(T)$. Let $t_{k}^{*}$ be the maximum level at which this property is satisfied. This maximum level is well defined because both $\underline{B}_{k}^{+}(T)$ and $B\left(t_{k}^{*}, \bar{w}(),. \bar{m}().\right)$ are compact, and the latter varies continuously with $t_{k}$.

We are now able to bracket the value of $\min _{i} I T\left(z_{i}, R_{i}\right)$, as stated below.

Proposition 7 Let $z$ be an incentive-compatible allocation generated by the tax function $T$. Then

$$
\min _{k} t_{k}^{*} \leq \min _{i} I T\left(z_{i}, R_{i}\right) \leq \min _{k} \min _{i \in P_{k}}\left[c_{i}-\frac{\bar{w} \circ m_{i}^{-1}\left(m_{i}\right)}{\underline{w} \circ m_{i}^{-1}\left(m_{i}\right)} y_{i}+\bar{m} \circ m_{i}^{-1}\left(m_{i}\right)\right] .
$$

Proof. Proposition 1 implies that, for every $k$,

$$
t_{k}^{*} \leq \min _{i \in k} I T\left(z_{i}, R_{i}\right) \leq \min _{i \in P_{k}}\left[c_{i}-\frac{\bar{w}_{N} \circ m_{i}^{-1}\left(m_{i}\right)}{\underline{w} \circ m_{i}^{-1}\left(m_{i}\right)} y_{i}+\bar{m}_{N} \circ m_{i}^{-1}\left(m_{i}\right)\right] .
$$

The conclusion then follows from the fact that

$$
\min _{i \in N} I T\left(z_{i}, R_{i}\right)=\min _{k} \min _{i \in k} I T\left(z_{i}, R_{i}\right),
$$

and from the fact that when for all $k \in K, a_{k} \leq x_{k} \leq b_{k}$, then

$$
\min _{k} a_{k} \leq \min _{k} x_{k} \leq \min _{k} b_{k} .
$$

Note that in every subgroup $k$, the $m_{i}$ function is known and identical across agents belonging to the subgroup. With some preference diversity assumption one can easily simplify the upper bound so as to take all bundles such that $y_{i} \leq \underline{w} \circ m_{i}^{-1}\left(m_{i}\right)$, in a similar fashion as done earlier.

As far as optimal tax is concerned, the result of the previous section applies to every subgroup $k$ separately. What is new is that an optimal tax will equalize $\min _{i \in k} I T\left(z_{i}, R_{i}\right)$ across $k$. This is not the same as equalizing $t_{k}^{*}$ across $k$, because in absence of preference diversity, one may have $t_{k}^{*}<\min _{i \in k} I T\left(z_{i}, R_{i}\right)$ for some $k$. 


\section{Conclusion}

This paper proposes a very general model in which earnings and human capital expenditures provide the basis for a redistribution policy that respects individual choices on labor and human capital, but seeks to eliminate inequalities due to inter-individual differences in the intrinsic cost to acquire human capital and in earning ability conditional on human capital.

Our main intent is to contribute to the theory of tax reform (Feldstein [11]). The idea is to see how certain ideas of fairness lead to the evaluation of arbitrary tax policies in such a general model. We find that the policy maker should primarily be interested in the part of the budget set that is attainable by agents endowed with the worst personal circumstances. Interestingly, the worst-off agent, at any arbitrary incentive compatible allocation, needs not be one of such agents. In typical circumstances (in particular, when the marginal tax rate on income is less than 100 percent), the part of the budget set that should be the focus of attention corresponds to the full time earnings of an agent from the worst type, at a level of human capital expenditures defined in terms of post-tax productivity of human capital expenditures.

The paper also contributes to the theory of optimal taxation. We look both at linear and non linear tax schemes. The main difference between the two cases is that in the former human capital expenditure might be always taxed while in the latter case human capital expenditures are subsidized on the margin, up to a level of expenditures defined in reference to the agents who receive the greatest absolute amount of subsidy.

Several extensions of this analysis can be considered. First, our analysis has ignored risk in the production of human capital and in the returns to human capital on the labor market. However, we believe that our analysis covers the most relevant case of pure idiosyncratic risk, i.e., when the policy-maker is able to predict the distribution of individual situations. It is then more respectful of the individuals' preferences to take account of this distribution rather than just the individual ex ante prospects, because what the individuals care about is their final situation.

Another extension would consider more than one dimension of human capital. While our model can be applied to education or health, it cannot be applied to both dimensions simultaneously, unless they are lumped together into a single human capital variable. The extension of the social ordering function to dimensional human capital is straightforward, but the application to tax evaluation is less obvious because two kinds of expenditures can then be distinguished by the tax 
function.

A key feature of our approach, which helps a lot in obtaining results in such a general model, is the absolute priority granted to the worst-off. One may find that indexing well-being by moneymetric utilities $I T_{i}\left(z_{i}^{*}, R_{i}\right)$ is sensible but resist the absolute priority. It would be interesting to see what happens to the results when a strong but finite degree of priority replaces the maximin criterion in the evaluation of taxes. This would imply paying attention to levels of income above the levels accessible to the worst type.

Finally, actual policies are segmented and specific tax-subsidy functions operate separately on income and human capital expenditures. Our analysis of reform evaluation, fortunately, carries over to this case which is a subclass of the arbitrary tax functions studied here. The analysis of optimal linear tax, by construction, happens to satisfy this separation property. But such is not the case for optimal non-linear taxation. The methodology of Proposition 5 cannot be applied because for an optimal tax function $T^{*}$ that is additively separable in earnings and human capital expenditures, the new tax function $T^{* *}$ that cuts all subsidies above a fixed level loses this property.

\section{Appendix}

We list here the axioms that characterize the social welfare function used in the paper. For a description of the normative implications of the axioms and for a formal proof of the characterization one can see Valletta [39]).

Strong Pareto: For all $e \in \mathcal{D}, z, z^{\prime} \in Z$ if, for all $i \in N, z_{i}^{\prime} R_{i} z_{i}$ then $z^{\prime} \widetilde{R}(e) z$. If moreover, for some $j \in N, z_{j}^{\prime} P_{j} z_{j}$ then $z^{\prime} \widetilde{P}(e) z$.

Equal Well-being for Equal Preferences For all $e \in \mathcal{D}, z, z^{\prime} \in Z$, if there exist $i, j \in N$ and some $\Delta>0$, such that $R_{i}=R_{j}, l_{i}=l_{j}=l_{i}^{\prime}=l_{j}^{\prime}, h_{i}=h_{j}=h_{i}^{\prime}=h_{j}^{\prime}$ with $z_{k}=z_{k}^{\prime}$ for all $k \neq i, j$,

$$
c_{i}-\Delta=c_{i}^{\prime}>c_{j}^{\prime}=c_{j}+\Delta
$$

then $z^{\prime} \widetilde{P}(e) z ;$ if otherwise

$$
c_{i}^{\prime}=c_{j} \text { and } c_{i}=c_{j}^{\prime}
$$


then $z^{\prime} \widetilde{I}(e) z$.

Uniform Circumstances Neutrality: For all $e \in \mathcal{D}, z, z^{\prime} \in Z$, if for all $i, j \in N, w_{i}()=.w_{j}($.$) ,$ $m_{i}()=.m_{j}($.$) , and if there exist m, n \in N$ and some $\Delta>0$ such that, $\left.z_{m} \in \max \right|_{R_{m}} B\left(t_{m}\right.$, $\left.w_{m}(),. m_{m}().\right),\left.z_{m}^{\prime} \in \max \right|_{R_{m}} B\left(t_{m}^{\prime}, w_{m}(),. m_{m}().\right),\left.z_{n} \in \max \right|_{R_{n}} B\left(t_{n}, w_{n}(),. m_{n}().\right),\left.z_{n}^{\prime} \in \max \right|_{R_{n}}$ $B\left(t_{n}^{\prime}, w_{n}(),. m_{n}().\right)$, with $z_{k}=z_{k}^{\prime}$ for all $k \neq m, n$,

$$
t_{m}-\Delta=t_{m}^{\prime}>t_{n}^{\prime}=t_{n}+\Delta
$$

then $z^{\prime} \widetilde{P}(e) z ;$ if otherwise

$$
t_{m}^{\prime}=t_{n} \text { and } t_{m}=t_{n}^{\prime}
$$

then $z^{\prime} \widetilde{I}(e) z$.

Independence: For all $z, z^{\prime} \in Z$, e, $e^{\prime} \in \mathcal{D}$, with $e=(R, w, m)$ and $e^{\prime}=\left(R^{\prime}, w, m\right)$, if for all $i \in N$ and $q \in Z$,

$$
\begin{aligned}
& z_{i} I_{i} q \Longleftrightarrow z_{i} I_{i}^{\prime} q \\
& z_{i}^{\prime} I_{i} q \Longleftrightarrow z_{i}^{\prime} I_{i}^{\prime} q
\end{aligned}
$$

then

$$
z^{\prime} \widetilde{R}(e) z \Longleftrightarrow z^{\prime} \widetilde{R}\left(e^{\prime}\right) z
$$

For any $S \subseteq N$ let $\bar{m}_{S}()=.\frac{1}{|S|} \sum_{j \in S} m_{j}($.$) and \bar{w}_{S}()=.\frac{1}{|S|} \sum_{j \in S} w_{j}($.$) denote, respectively, the$ average health disposition mapping and the average earning ability mapping within the group $S$. For the ease of notation let $\bar{m}_{N}()=.\bar{m}($.$) and \bar{w}_{N}()=.\bar{w}($.$) .$

Separation: For all $e \in \mathcal{D}$ and for all $z, z^{\prime} \in Z$, if there is $S \subseteq N$ such that $\bar{m}_{S}()=.\bar{m}($.$) ,$ $\bar{w}_{S}()=.\bar{w}($.$) and, for all i \in S, z_{i}=z_{i}^{\prime}$ then

$$
z^{\prime} \widetilde{R}(e) z \Longleftrightarrow z_{-S}^{\prime} \widetilde{R}\left(R_{-S}, w_{-S}(.), m_{-S}(.)\right) z_{-S} .
$$

Theorem: On the domain $\mathcal{D}$ a social ordering function satisfies Strong Pareto, Equal Well-being 
for Equal Preferences, Uniform Circumstances Neutrality, Independence and Separation, if and only if it is an Average Circumstances Egalitarian Equivalent Leximin function.

\section{References}

[1] A. B. Atkinson, J.E. Stiglitz, The design of tax structure: direct versus indirect taxation, Journal of Public Economics, 6(1976), 55-75.

[2] A. Blomqvist, H. Horn, Public Health Insurance and Optimal Income Taxation, Journal of Public Economics, 24(1984), 352-371.

[3] R. Boadway, L. Jacquet, Optimal Marginal and Average Income Taxation under Maximin, Journal of Economic Theory, 143(2008), 425-441.

[4] R. Boadway, M. Marchand, P. Pestieau, M. Racionero, Optimal Redistribution with Heterogeneous Preferences for Leisure, Journal of Public Economic Theory, 4(2002), 475-498.

[5] R. Boadway, P. Pestieau, Indirect Taxation and Redistribution: The Scope of the AtkinsonStiglitz Theorem, in Richard Arnott, Bruce Greenwald, Ravi Kanbur and Barry Nalebuff (eds.), Economics for an Imperfect World: Essays in Honor of Joseph E. Stiglitz, MIT Press (2003).

[6] A. L. Bovenberg, B. Jacobs, Redistribution and Education Subsidies are Siamese twins, Journal of Public Economics, 89(2005) 2005-2035

[7] P. Choné, G. Laroque, Optimal incentives for labor force participation, Journal of Public Economics, 89(2005), 395-425.

[8] P. Choné, G. Laroque, Negative Marginal Tax Rates and Heterogeneity, American Economic Review, 100(2010), 253247.

[9] H. Cremer, P. Pestieau, Redistributive Taxation and Social Insurance, International Tax and Public Finance, 3(1996), 281-295.

[10] K. Christensen, N. V. Holm, M. Mcgue, L. Corder, J. W. Vaupel, A Danish Population-Based Twin Study on General Health in the Elderly, Journal of Aging and Health, 11(1999), 49-64. 
[11] M.S. Feldstein, On the theory of tax reform, Journal of Public Economics 6(1976), 77-104.

[12] M. Fleurbaey, Health, Wealth and Fairness, Journal of Public Economic Theory, 7(2005), 253-284.

[13] M. Fleurbaey, Is commodity taxation unfair?, Journal of Public Economics 90(2006), 17651787.

[14] M. Fleurbaey, Fairness, responsibility and welfare. Oxford University Press (2008).

[15] M. Fleurbaey, F. Maniquet, Fair social orderings when agents have unequal production skills, Social Choice and Welfare 24(2005), 93-127.

[16] M. Fleurbaey, F. Maniquet, Fair Income Tax, Review of Economic Studies, 73(2006), 55-83.

[17] M. Fleurbaey, F. Maniquet, Help the low-skilled or let the hardworking thrive? A study of fairness in optimal income taxation, Journal of Public Economic Theory 9(2007) 467-500.

[18] M. Fleurbaey, F. Maniquet, A Theory of Fairness and Social Welfare, Cambridge University Press (2011).

[19] M. Fleurbaey, F. Maniquet, Utilitarianism versus fairness in welfare economics, in M. Salles and J. A. Weymark (eds), Justice, Political Liberalism and Utilitarianism: Themes from Harsanyi and Rawls, Cambridge U. Press, forthcoming.

[20] M. Fleurbaey, F. Maniquet, Compensation and responsibility, in K.J. Arrow, A.K. Sen and K. Suzumura (Eds), Handbook of Social Choice and Welfare V. II, North-Holland, forthcoming.

[21] M. Grossman, L. Benham, Health, Hours and Wages, M. Perlman (ed.), The Economics of Health and Medical Care. Macmillan and Co., London (1974).

[22] R. Guesnerie, A contribution to the pure theory of taxation, Cambridge University Press (1995).

[23] D. Henriett, J.C. Rochet, Is Public Health Insurance an Appropriate Instrument for Redistribution?, Annales d'economie et de statistique, 83-84(2006), 61-88.

[24] B. Jacobs, A. L. Bovenberg, Optimal Taxation of Human Capital and the Earnings Function, CESifo Working Paper No. 2250. 
[25] B. Jacobs, A. L. Bovenberg, Optimal Taxation of Human Capital and the Earnings Function, Journal of Public Economic Theory 13(2011), 957-971

[26] L. Jacquet, D. Van de gaer, A Comparison of Optimal Tax Policies when Compensation or Responsibility Matter, Journal of Public Economics (forthcoming).

[27] D. Krueger, A. Ludwig, Optimal Progressive Taxation and Education Subsidies in a Model of Endogenous Human Capital Formation, mimeo.

[28] H. Luft, The Impact of Poor Health on Earnings. Review of Economics and Statistics, 57 (1975), 43-57.

[29] D. Maldonado, Education Policies and Optimal Taxation, International Tax and Public Finance, 15(2008), 131-143.

[30] M.G. Marmot, G. Davey Smith, S. Stansfeld, C. Patel, F. North, J. Head, I. White, E. Brunner, A. Feeney, Health inequalities among British civil servants: the Whitehall II study, Lancet 337(1991), 1387-1393.

[31] J. Mirrlees, An exploration in the theory of optimum income taxation, Review of Economic Studies 38(1971), 175-208.

[32] S. Mushkin, Health as an Investment, Journal of Political Economy 70(1962), 129-157.

[33] T. Piketty, E. Saez, Optimal Labor Income Taxation, NBER Working Paper 18521.

[34] D.D. Reid, G.Z. Brett, P.J.S. Hamilton, R.J. Jarrett, H. Keen, G. Rose, Cardio-respiratory disease and diabetes among middle-aged male civil servants: a study of screening and intervention. Lancet 303(1974), 469-473.

[35] J.C. Rochet, The taxation principle and multi-time Hamilton-Jacobi equations, Journal of Mathematical Economics, 14(1985), 113-128.

[36] J.C. Rochet, Incentives, Redistribution and Social Insurance, Geneva Papers on Risk and Insurance Theory, 16(1991), 143-165.

[37] E. Saez, Optimal income transfer programs: intensive versus extensive labor supply responses, Quarterly Journal of Economics, 117(2002), 1039-1073. 
[38] E. Saez, S. Stantcheva, Generalized social marginal welfare weights for optimal tax theory, mimeo (2013).

[39] G. Valletta, Health, fairness and taxation, CORE DP 16 (2012) 